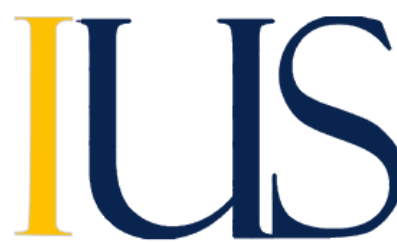

Revista de Investigación de la Facultad de Derecho

\title{
Inclusión de la modalidad de acogimiento post adoptivo, en la ley 30162 a favor de los niños abandonados en el Perú.
}

\author{
Inclusion of post-adoptive foster care in Law 30162 in favor of \\ abandoned children in Peru.
}

Yulissa Johanna Tineo Espino *, 1, a yulissatineoespino@gmail.com https://orcid.org/0000-0002-6748-1465

\author{
Investigadora Independiente, \\ ${ }^{1}$ Abogada por la Universidad Católica Santo Toribio de \\ Mogrovejo, Chiclayo, Perú
* Universidad Católica Santo Toribio de Mogrovejo
${ }^{2}$ Abogada, Magister en Derecho Civil y Docente de la Facultad de Derecho de la Universidad Católica Santo \\ Toribio de Mogrovejo
}

Dora Ojeda Arriarán *, 1, a

yulissatineoespino@gmail.com

https://orcid.org/0000-0002-6748-1465

Fechas importantes

Recibido: 2021-07-14

Aceptado: 2021-07-19

Publicado online: 2021-07-31

\section{Resumen}

El acogimiento familiar ofrece a los niños la posibilidad de vivir en un ambiente familiar, cuando su familia de origen no se encuentra en condiciones de hacerlo o están atravesando por múltiples circunstancias que impiden la permanencia con sus hijos. El marco Jurídico y las legislaciones nacionales e internacionales, sobre el acogimiento familiar, han previsto que la familia es el entorno más favorable para el menor donde puedan vivir, crecer y desarrollarse, debido a su estado de vulnerabilidad propio de su edad. Sobre esa base, en este estudio se propone la necesidad de incluir la modalidad de acogimiento post adoptivo, en la ley 30162 a favor de los niños(as) y adolescentes abandonados, entonces habrá un mayor número de niños acogidos y por ende existirán más familias motivadas a pertenecer al programa de acogimiento familiar, debido a que el legislador ha considerado únicamente el Acogimiento familiar de carácter temporal. 
Palabras clave: Acogimiento familiar Acogimiento post adoptivo Estado de vulnerabilidad Estado de abandono Acogimiento temporal

\begin{abstract}
Foster care offers children the possibility of living in a family environment, when their family of origin is not in a position to do so or they are going through multiple circumstances that prevent them from staying with their children. The legal framework and national and international laws on foster care have provided that the family is the most favorable environment for the minor in which they can live, grow and develop, due to their state of vulnerability inherent to their age. On that basis, this study proposes the need to include the modality of post-adoptive foster care, in Law 30162 in favor of abandoned children and adolescents, then there will be a greater number of foster children and therefore there will be more families motivated to belong to the foster care program, because the legislator has only considered temporary foster care.
\end{abstract}

Keywords: Foster care Post adoptive foster care State of vulnerability State of abandonment

\title{
Introducción
}

Uno de los derechos fundamentales de los niños, niñas y adolescentes es el derecho a tener una familia, sin embargo existen múltiples circunstancias en la cual el menor se encuentra en desprotección familiar, es por esto que el estado como ente protector, ha creado medidas de protección como el acogimiento familiar, sin embargo son muchos más los niños que se encuentran institucionalizados que en familias acogedoras, esto debido a que el legislador ha considero únicamente el Acogimiento familiar de carácter transitorio y no el acogimiento familiar post adoptivo.

Según la entrevista realizada al director de INABIF José Antonio Córdova Prado, en el momento que se realiza la entrevista a las familias acogedoras, surge la inquietud sobre la posibilidad de realizar la adopción luego de terminado el plazo del acogimiento y al explicarles que no existe dicha posibilidad se genera una gran desmotivación y posteriormente estas familias terminan desistiendo, debido a que las familias son conscientes de que vivir con un niño implica la creación de fuertes lazos afectivos, siendo así difícil la separación del niño con su familia acogedora; ademas esta situación vulnera el interes superior del niño pues implicaria una doble perdida familiar.

Es por ello que en la presente investigación nos planteamos la siguiente interrogante ¿Cómo beneficiaria incluir la modalidad post adoptiva en el acogimiento familiar (Ley No 30162), con el propósito de proteger a los niños declarados en estado de abandono a la luz del principio del interés superior del niño?

Si se incluye una nueva modalidad de acogimiento familiar, en la Ley 30162, como "Acogimiento Post Adoptivo", entonces habrá un mayor número de niñas, niños y adolescentes acogidos que están declarados en estado de abandono y existirán más familias motivadas a pertenecer al programa de acogimiento familiar de INABIF, permitiéndoles tener una familia junto a su familia acogedora, evitando la reinserción del niño en los centros de atención residencial, considerando a la institucionalización como último ratio, ya que conllevan toda una serie de déficits psicológicos y afectivos que marcan profundamente la personalidad del menor. No obstante, el Estado, a través del programa del acogimiento familiar, ofrece a los niños la posibilidad de vivir en un ambiente familiar, ya que el niño(a) o adolescente es un sujeto de derecho de protección especial que requiere de asistencia y cuidado adecuados, necesarios y especiales para su desarrollo.

Así mismo, las legislaciones nacionales e internacionales respecto al acogimiento familiar; han previsto que la familia es el entorno más favorable para el menor donde puedan vivir, crecer y desarrollarse, debido a su estado de vulnerabilidad propio de su edad. Países como (España, 
chile, México, Paraguay, Colombia, Bolivia y Ecuador), en relación al acogimiento familiar, consideran una serie de modalidades de acogida (acogimiento simple, transitorio y adoptivo), cabe resaltar la modalidad de acogimiento adoptivo; modalidad que pretendemos incluir en la Ley de acogimiento familiar No 30162 del Perú, considerando el impacto positivo en otros países mencionados líneas arriba, trayendo consigo un mayor número de niñas, niños y adolescentes acogidos.

Mientras tanto, en la Ley de acogimiento familiar No 30162 del Perú, en su artículo N07 apartado $\mathrm{F}$, menciona como exclusiones de acogimiento familiar que la familia acogedora no puede posteriormente solicitar la adopción ya que esto es una medida de protección transitoria y la familia acogedora no podrá acceder a la adopción del niño(a) o adolescente acogido y tendrá que regresar a los centros de atención residencial.

En consecuencia, la exclusión de las familias acogedoras como aspirantes a la adopción del menor acogido, atenta contra el principio del interés superior del niño y vulnera su derecho fundamental a vivir en una familia, al negarle la posibilidad de que en determinadas circunstancias, puedan ser adoptados por sus acogedores familiares, con quienes ya viven una experiencia de familia llegando a ocasionar innecesariamente un segundo desarraigo familiar al menor, con las consiguientes repercusiones en su salud emocional, bienestar físico y su desarrollo integral; siendo necesario la modificación de la ley de acogimiento familiar, a efectos que sea permitido tener acceso a la adopción del menor acogido

\section{El acogimiento familiar como garantía del derecho del niño y deber esencial del estado}

\subsection{Nociones preliminares del Acogimiento familiar}

El acogimiento familiar es la convivencia de un menor con una familia distinta a la suya, dado que no pueden convivir con su familia biológica, garantizándole así un entorno más adecuado en el que pueda crecer, vivir y desarrollarse.

Desde fechas inmemorables, se ha venido realizado la institucionalización de los niños y adolescentes. "Durante la mayor parte del siglo XX, hasta los años ochenta, la protección de los menores de edad en situación "carencial"; se basó en la institucionalización de niños y adolescentes" (Del valle, 2009). Es decir, que cuando un niño y adolescente carecía de familia o se encontraba en estado de peligro, abandono material, sin educación y los cuidados necesarios; la mejor solución alternativa que presentaba era separar a dicho niño, recluyéndolo en una institución. Por estas razones, la legislación otorga como respuesta legal la institucionalización de estos menores de edad.

Más adelante, se vio que la institucionalización de los menores en grandes centros en situación de desamparo no era la mejor solución, ya que conllevaba toda una serie de déficits psicológicos y afectivos que marcaban profundamente la personalidad del menor, por lo que había que buscar nuevas alternativas; proponiéndose el Acogimiento familiar (Jiménez, 2001). Teniendo como alternativa al acogimiento familiar, con la finalidad de evitar la institucionalización de los niños tras antecedentes de déficits de los centros de atención residencial.

En la actualidad en el Perú, la Ley 30162 - Ley de acogimiento familiar "Ofrece a los niños y adolescentes, la posibilidad de vivir transitoriamente en un ambiente familiar que les servirá de modelo de vida familiar, de escuela para elegir como vivir cuando decidan formar una 
familia, de espacio de equipamiento con las herramientas y habilidades necesarias para la vida, de un nuevo referente familiar para su vida" (Instituto Nacional de Bienestar Familiar, 2013). Esta Ley busca que los niños y adolescentes que por algún motivo no puedan vivir con sus padres o se encuentren en situación de abandono familiar, puedan ser integradas de manera excepcional y temporal a un núcleo familiar extenso o a uno no consanguíneo, que les permite la restitución, el disfrute, goce y ejercicio de su derecho a vivir en una familia que les provea de las cualidades necesarias para su desarrollo integral.

Considerado al acogimiento familiar como "Aquella figura jurídica por la que se integra a un menor en una familia que no es la constituida por sus padres biológicos. Los Acogedores tienen todas las obligaciones, esto es, de velar por él, tenerlo en su compañía, alimentarlo, educarlo, procurarle una formación integral y, sobre todo afectiva (Baldo,2005). Desde esta perspectiva, la familia acogedora cumplirá las mismas funciones que los padres biológicos frente al menor.

Es un proceso que posibilita el derecho que todo niño y adolescente a vivir en familia, cuando existen impedimentos para hacerlo en la propia. "El programa estimula el desarrollo de la persona en el marco del respeto de su identidad y sus vínculos afectivos; previniendo su institucionalización (internación). Es un recurso de apoyo temporal en situaciones en que la convivencia con la familiar de origen no es posible, por tanto, se trata de asegurar el desarrollo del niño o adolescente en un entorno familiar" (Programa de Acogimiento Familiar, 2014). Totalmente de acuerdo de que el niño viva, crezca y se desarrolle en el seno de una familia, siendo una parte muy importante de nuestras vidas, nos ayuda a mejorar nuestra personalidad y a formar nuestro carácter; nos enseña el valor del amor, afecto, cariño, honradez y auto confianza, y nos provee con las herramientas necesarias para tener éxito en la vida. En este sentido, el acogimiento familiar se nos presenta como una herramienta muy útil ante las situaciones de emergencia que se han suscitado, respecto a temas de desprotección familiar de aquellos niños y adolescentes.

Para Aliaga (2013), son los padres los que deben ser el núcleo protector de los niños y adolescentes y los obligados directos y comprometidos con el desarrollo integral de sus hijos; sin embargo, algunas veces no pueden o no quieren cumplir con ese rol y sus hijos terminan viéndose privados de sus cuidados parentales ". Es preocupante que los propios padres sean los que vulneren los derechos fundamentales de sus hijos, principalmente el derecho a la identidad, el derecho a la integridad física y psíquica; es aquí donde el estado entra a tallar, siendo el acogimiento familiar la medida de protección más adecuada frente a la desprotección familiar de los niños; brindando así una especial protección; considerando que el entorno más conveniente es la familia, siendo el primer lugar de crecimiento del ser humano, de seguridad, en el que aprenderá los primeros comportamiento y valores; evitando así la institucionalización del menor.

Concluimos este apartado señalando que el acogimiento familiar; es la convivencia de un menor con una familia distinta a la suya, dado que por algún motivo no puedan vivir con sus padres o se encuentren en situación de abandono familiar, permitiéndoles la restitución, el disfrute, goce y ejercicio de su derecho a vivir en una familia que les provea de las cualidades necesarias para su desarrollo integral; garantizándole así un entorno más adecuado en el que pueda crecer, vivir y desarrollarse.

\subsection{Actores implicados en el acogimiento familiar}

\subsubsection{Los niños y adolescentes beneficiados por el acogimiento familiar}

Es preciso señalar que las características fueron obtenidas en una entrevista realizada a la licenciada en sociología Ariana Silva Gálvez encargada del equipo de seguimiento del área de 
acogimiento familiar de INABIF Lima: " El perfil de estos niños acogidos está determinado por el ambiente de violencia que vivió con sus familias de origen, violencia que en algunos casos los convirtieron en niños tímidos y sin autoestima o por el contrario en niños con una actitud agresiva y desconfiada " (Silva, 2016). Perfiles presenciados en los niños que sufren desprotección familiar por parte de sus padres.

La socióloga comentó sobre el Síndrome del niño invisible detectado en estos niños: "Siendo un trastorno de conducta infantil volviéndolo distante, irritable, fantasioso, aislado y retraído. Son sólo algunos de los síntomas del 'Niño invisible', un trastorno en la conducta del niño que no se siente valorado y querido por las personas que le rodean y demanda de esta forma más atención. Son niños retraídos y muy imaginativos, que buscan en su mundo de fantasía un lugar donde sentirse cómodos" (Silva, 2016). Razón por la cual es necesario por parte de la familia acogedora ofrecerle cariño, amor, consuelo cuando tenga miedo, una comunicación más cercana para que exprese sus sentimientos esto ayudara al reforzamiento de su autoestima, debido a la presencia de serias carencias afectivas por parte de familia de origen.

Se señala en la Constitución, artículo 4, que la comunidad y el Estado protegen especialmente al niño, al adolescente. "El fundamento constitucional de la protección del niño y del adolescente que su constitución les otorga, radica en la especial situación en que ellos se encuentran" Es decir, en plena etapa de formación integral en tanto personas (Jurisprudencia Justicia Penal Juvenil, 2010). En tal sentido, el Estado, además de proveer las condiciones necesarias para su libre desarrollo, debe también velar por su seguridad y bienestar.

A modo de conclusión, corresponde señalar que el perfil de estos niños y adolescentes acogidos está determinado por un entorno de ausencia de cuidados parentales, motivo por el cual es importante que por parte de la familia acogedora llegue a brindarle los cuidados necesarios, para su correcto desarrollo integral del menor.

\subsubsection{Las familias de origen de los niños y adolescentes en estado de abandono}

Por lo tanto "La mayoría de niños que son acogidos, provienen de familias donde los padres son violentos o toxicómanos, consumo excesivo de sustancias, tensión de la relación en familias ensambladas, problemas educativos, descuido en la atención de enfermedades" (Losanto,2017). Estas situaciones conllevan a la separación del menor de sus padres biológicos, esto deberá proponerse cuando se constate la presencia de una o varias de las circunstancias mencionadas, encontrándose al menor en un estado de total desprotección familiar o peligro.

Siguiendo esta línea, FERIA (2014) considera que los niños acogidos provienen también de familias con carencia de recursos, negligencia o falta de habilidades en el cuidado de los niños, violencia doméstica, enfermedades mentales, privación de libertad, hospitalización prolongada etc.

Consideramos al acogimiento familiar como una alternativa que busca hogares temporales para que los niños y adolescentes puedan crecer y desarrollarse en el seno de una familia, pues al permanecer es este ambiente familiar se encuentran expuestos a una mayor cantidad de riesgos como, por ejemplo: maltrato, delincuencia, prostitución, tráfico de drogas, etc., siendo estos, los más vulnerables frente a estos problemas sociales. (Mella, 2014). Asimismo; el mejor lugar para que el niño, crezca, viva y se desarrolle es la familia, permitiendo su desarrollo integral, donde no solo obtendrá la satisfacción de sus necesidades de alimentos, salud, educación, sino también afectivas, sintiéndose querido, amado, respetado, escuchado; formando de manera positiva el desarrollo de su personalidad, así como el forjamiento de valores y virtudes inculcados en el entorno familiar, restaurando su autoestima, 
empoderándolos frente a la vida.

Para finalizar este apartado, se considera que las familias de origen de los niños y adolescentes en estado de abandono, son familias que atraviesan por múltiples circunstancias que impiden la permanencia con sus hijos y es a través del programa de acogimiento familiar, donde se otorgara al menor la oportunidad de vivir en una familia.

\subsubsection{Las familias beneficiadas en el acogimiento familiar}

Las familias acogedoras son personas de buen corazón, que quieren acoger a un niño y hacer que formen parte de su hogar, tratándoles como un hijo más y no solo satisfaciendo sus necesidades de alimentación, educación, salud, vestimenta, sino también afectivas, brindándoles amor, cariño debido a las serias carencias afectivas por parte de su familia de origen.

Según la entrevista realizada a la licenciada en sociología Ariana Silva Gálvez encargada del equipo de seguimiento del área de acogimiento familiar de INABIF Lima: Existen casos muy frecuentes de familias acogedoras (Familias Extensas: Consanguíneas), como por ejemplo que en mayor medida nos encontramos que los acogedores son los abuelitos del menor o las tías maternas (Silva, 2016). Son las familias consanguíneas quienes acogen en mayor medida a los niños que se encuentran en estado de desprotección familiar por parte de sus padres biológicos.

Al respecto, JIMENEZ (2008) refirió que en Europa ocurre un caso parecido donde un estudio revelo que por lo que respecta al parentesco, en los acogimientos en familia extensa Predominan: "Las abuelas y los abuelos. En el estudio de Valencia (Molero et al. 2007) eran el 70,3\%, en el de Barcelona (Montserrat, 2006) el 73,5\%, en el de Asturias (Del Valle et al. 2002 ) el $80 \%$, en Andalucía (Palacios y Jiménez, 2007) el 55\%, en Italia (Centro Nazionale di Documentazione, 2002) el 57,9\%. Siguen en segundo lugar, pero a distancia, los tíos y tías en Asturias (15\%), Barcelona (18\%), Valencia (21,3\%), Andalucía (38\%) e Italia (38,2\%). Predomina también la familia materna frente a la paterna: en los estudios de Valencia el $54,5 \%$, en Andalucía el 55\%, en Asturias el $61,9 \%$ y en el de Barcelona el $63 \%$. También en otros estudios vemos en primer lugar las abuelas maternas, seguidas de las tías maternas (Dubowitz, Feigelman y Zuravin, 1993; Prohn Le, 1994; Scannapieco, 1999; Thornton, 1991).

En este apartado el equipo técnico del acogimiento familiar, estudiara los perfiles de las familias acogedoras, seguidamente se tomará contacto con la familia preferente y en el caso de empatía no resulte, se contactará con la segunda familia acogedora seleccionada. Se programará una sesión con la familia seleccionada y el equipo técnico de la entidad ejecutora del programa de acogimiento familiar, se informará a la familia sobre las características sociales y psicosociales del menor (Manual de acogimiento familiar, 2014). Es decir, de manera inicial se hace una selección de una o dos familias, con la finalidad de encontrar a la familia con el perfil idóneo y pueda realizar el acogimiento familiar.

A modo de conclusión, corresponde señalar, que las familias acogedoras beneficiadas en el acogimiento familiar, deben proteger y respetar derechos del menor, comunicar inmediatamente a la autoridad competente situaciones especiales que se presenten y asistir a las capacitaciones correspondientes; deberes muy importantes y el no cumplimiento de estas obligaciones es considerado como una falta de responsabilidad y compromiso debido a que tenemos que velar por el interés superior del niño. 


\subsection{Tipología nacional del acogimiento familiar reconocida en la Ley N 30162}

\subsubsection{Acogimiento de familia no consanguínea}

El acogimiento de familia no consanguínea es conocido también como acogimiento coyuntural, principalmente es debido a los contextos en los cuales un menor es acogido en una estructura familiar con la cual no le unen vínculos sanguíneos (Cárdenas, 2014).

Mediante esta medida de protección los niños y adolescentes son acogidos por personas idóneas que sin tener parentesco alguno constituyen un entorno positivo y apropiado para la protección del menor, este será otorgado teniendo en cuenta la relación de afinidad o afectividad con el niño o adolescente que pretende asumir su acogimiento.

\subsubsection{Acogimiento especial}

Es considerado también como un "Acogimiento de urgencia, en la cual generalmente los familiares sanguíneos acuden en auxilio del menor cobijándolo en su hogar". Dicho acogimiento es emitido mediante resolución judicial a través de la Dirección de Investigación Tutelar, con la finalidad de que estos niños no sean institucionalizados, es decir enviados a los CARS, siendo INABIF, el encargado de evaluar a través de su equipo técnico a la supuesta familia acogedora. Mediante esta medida de protección se dispone el acogimiento del niño y adolescente en su familia extensa, considerando a los abuelos y parientes hasta el cuarto grado de consanguinidad y segundo de afinidad; con la finalidad de sustituir temporalmente su núcleo familiar y asumir las responsabilidades de la tutela (Asociación Estatal de Acogimiento Familiar, 2010).

Para finalizar este apartado, se considera que el acogimiento de familia especial, se otorga ante una situación de urgencia, en la cual generalmente los familiares sanguíneos acuden en auxilio del menor cobijándolo en su hogar. El acogimiento especial es caracterizado porque tiene lugar mientras se realiza el estudio del menor y su familia biológica, evitando ser institucionalizados en los centros de atención residencial

\subsection{Procedimiento del acogimiento familiar}

La ley de acogimiento familiar (2014), regula dos procedimientos para así poder solicitar el acogimiento familiar.

\subsubsection{Procedimiento administrativo}

Respecto al procedimiento administrativo, se determina lo siguiente:

a) Competencia - Se solicita ante la Dirección de Investigación Tutelar del Ministerio de la Mujer y Poblaciones Vulnerables.

b) Solicitud. - Debe adjuntarse la opinión favorable del INABIF, para lo cual se presenta antes una solicitud ante esta entidad.

c) Evaluación -

Dicha evaluación comprende los aspectos psicológicos, sociales y legales de los solicitantes.

La Dirección de Investigación Tutelar otorgara el acogimiento familiar, previa evaluación social, psicológica y constatación domiciliaria, sin perjuicio de los requisitos establecidos por su reglamento. Para este efecto, deberá considerar prioritariamente el grado de parentesco y necesariamente la relación de afinidad o afectividad con la persona o familia que pretenda asumir su cuidado. También podrá disponer el acogimiento familiar en familiar previamente calificadas y registradas. 
Se aplicará la medida sobre la base de los respectivos informes del equipo técnico de Acogimiento familiar a cargo de la Unidad de Servicios de protección de Niños, Niñas y Adolescentes - INABIF.

Un dato relevante consiste en que "Se debe tener en cuenta la opinión del niño o adolescente tutelado, en función de su edad y grado de madurez, respecto de su deseo de ser acogido por los solicitantes.

\subsubsection{Procedimiento judicial}

a) Competencia. - Ante el juez que conoce la investigación tutelar del menor o directamente al juez de familia o al juez mixto.

b) Trámite. - Se tramita en cuaderno aparte siempre que exista un proceso de investigación tutelar abierto.

c) Solicitud. - La solicitud se presenta con los siguientes documentos:

- Copia del documento nacional de identidad.

- Certificado de antecedentes penales

- Certificado domiciliario.

- Certificado médico de salud con antigüedad no mayor de tres meses expedido por un centro de salud o institución autorizada, adjuntando los resultados de los exámenes VIH, VDRL Y rayos $X$ de pulmones.

- $\quad$-Copias de boleta de pago, recibo por honorarios u otro documento que sustente los ingresos económicos.

- Examen psicológico que evidencie salud mental y capacidad psicológica o emocional para el acogimiento familiar.

- Declaración jurada de no ser aspirante a la adopción.

- Certificado de no estar en el registro de deudores alimentarios morosos

Evaluación. - Se ha previsto que para el otorgamiento del acogimiento familiar se debe contar con dictamen favorable del fiscal competente y el informe positivo del equipo técnico multidisciplinario de la respectiva Corte Superior.

Se debe tener en cuenta la opinión del niño o adolescente tutelado, en función de su edad y grado de madurez.

d) Plazo para pronunciamiento. - Se ha previsto que el juez se pronuncie sobre el pedido de acogimiento en el plazo de treinta días hábiles.

Ambos procedimientos de acogimiento familiar (Administrativo y Judicial), coinciden que, de tratarse de un niño o adolescente, se encuentran en ejercicio de su libertad de opinión y el pleno derecho a la participación de aceptar o no la medida de protección.

A modo de acotación, es innegable reconocer que la finalidad del acogimiento familiar es promover el bienestar integral del niño o adolescente, atendiendo a sus posibles necesidades ya sean materiales o afectivas; fomentando el mantenimiento de su identidad familiar y dotándole de habilidades que le permitan desempeñar los roles correspondientes a su estado evolutivo, es por ello que los procedimientos de acogimientos familiar, se deben realizar con la celeridad posible para que el niño este lo más pronto posible en un entorno familiar, evitando la institucionalización del menor. 


\subsection{Organismos reguladores que buscan la protección de los niños y adolescentes a través del acogimiento familiar en el Perú.}

\subsection{1.- Inabif}

Instituto nacional de bienestar familiar (2016), ejerce funciones de órgano rector y por ende tiene a su cargo el programa de acogimiento familiar, a través de su equipo técnico es el encargado de realizar la elaboración y preparación de las familias acogedoras.

Las funciones que cumple el INABIF, de acuerdo a lo dispuesto en el Reglamento de Organización y Funciones del Ministerio de la Mujer y Poblaciones vulnerables, son las siguientes:

a) Dirigir y ejecutar acciones tendientes a lograr la prevención, protección, atención y apoyo de la población en riesgo, así como de bienestar familiar;

b) Administrar y supervisar las transferencias programáticas destinadas a la protección integral de la primera infancia de competencia.

c) Desarrollar y ejecutar los programas y servicios de prevención, asistencia, protección, y promoción relacionados con sus objetivos, así como los procedimientos necesarios para la consecución de los mismos;

d) Estimular la participación de la colectividad en acciones orientadas a mejorar las condiciones socioeconómicas y culturales de sus miembros;

e) Asumir las funciones establecidas para el MIMP con relación al voluntariado, su promoción y realización conforme a Ley;

f) Promover la gestión y el voluntariado comunal a favor de la niñez temprana y la población en riesgo, pobreza y pobreza extrema;

g) Velar por el interés superior de niños y adolescentes en materia de funcionamiento y ejecución de sus programas sociales;

h) Promover la protección integral de niños y adolescentes en riesgo o abandono, propiciando la generación y el mejoramiento de las condiciones que aseguren su desarrollo.

i) Desarrollar sistemas adecuados de prevención, promoción, asistencia y protección de niños(as) y adolescentes, especialmente de aquellos en situación de riesgo social.

j) Desarrollar acciones de prevención, atención y apoyo a las personas involucradas en hechos de violencia familiar y sexual;

k) Desarrollar servicios institucionales que ofrezcan a los niños y adolescentes en riesgo, las condiciones y posibilidades de su integración familiar y social;

I) Convocar e incentivar a la sociedad civil organizada y a la comunidad en general para su participación activa en la promoción, atención, apoyo a la población en riesgo o abandono y en desarrollar acciones a favor de la disminución y prevención de la violencia familiar y sexual;

m) Asumir las competencias establecidas para el MIMP en materia de la Investigación 
Tutelar.

n) Velar por el desarrollo de la gestión eficiente de los recursos humanos a su cargo, para el logro de sus objetivos y metas.

En conclusión, el Instituto nacional de bienestar familiar, será el encargado de monitorear a la familia acogedora; también se ha previsto supervisión periódica y permanente con el objetivo de evaluar el avance en el cumplimiento de las necesidades de educación, aprestamiento, reforzamiento, nivelación escolar, soporte emocional y social de los niños y adolescentes. De esta manera se podrá verificar si dichas necesidades se encuentran satisfechas durante el periodo de acogimiento familiar.

\subsection{2.- La Dirección de investigación tutelar como organismo complementario en el proceso de acogimiento familiar.}

Busca coordinar las acciones para la restitución de derechos y protección integral de los niños y adolescentes en situación de vulnerabilidad social.

Según el Ministerio de la Mujer y Poblaciones Vulnerables (MIMP, 2020), la dirección de investigación tutelar, tiene por finalidad Implementar un servicio de atención integral, multidisciplinario con metodología interdisciplinaria que priorice las necesidades de protección de los niños y adolescentes sin cuidados parentales, además está encargada de diseñar, promover y coordinar, supervisar y evaluar las políticas, planes, programas y proyectos en el campo de la niñez y la adolescencia. En ese sentido, resulta también importante destacar que el MIMP (2020) refirió que está encargada de llevar a cabo el procedimiento de investigación tutelar y verificar el presunto estado de abandono en que se encuentra una niña(o) 0 adolescente, conforme a las causas previstas en el artículo 248 del Código de los Niños y Adolescentes, aplicando la medida de protección más adecuada.

Ahora bien, para fines de la investigación corresponde señalar que la "Dirección de investigación tutelar", contribuye al bienestar y desarrollo integral del niño(a) o adolescente, que se encuentra en total desprotección familiar. Además de plantear políticas en protección de los niños, debido a su estado de vulnerabilidad. En ello encaja el acogimiento, dado que por ejemplo si deseamos exigir que se promueva o difunda más el acogimiento para aumentar el número de familias será este uno de los encargados en plantear una política de difusión y exigir al Ministerio encargado la toma de acciones correspondientes, situación necesaria debido a la escasa difusión y desconocimiento por parte de la sociedad, siendo lamentable el resultado anual de familias acogedoras a comparación con otros países.

\section{2.- El acogimiento familiar como restitución de derechos de los niños y adolescentes a vivir en familia según la legislación nacional y comparada}

Hoy en día resulta innegable que tanto las legislaciones, organismos nacionales como las internacionales brinden protección a los derechos del niño y reconozcan a la familia como institución constitucionalmente protegida, sino y, sobre todo, como derecho fundamental, viéndose en la obligación de implementar nuevas políticas que aceleren o introduzcan cambios positivos en la vida de los niños y adolescentes, siendo estos, los más vulnerables frente a estos problemas sociales.

\section{1.- Medios de protección nacional}




\subsection{1.- Legislación nacional}

\section{A) La constitución Política del Perú y su especial protección a la familia}

La Constitución Política del Perú reconoce el derecho a la vida (artículo 2 inciso 1), en el caso de los niños, comprende el derecho a vivir, crecer y desarrollarse en el seno de su familia natural y en caso de carecer de ella, a crecer en un ambiente familiar adecuado (Lopera, 2015). Esto justificaría la existencia de leyes y programas que protejan el derecho fundamental a la vida en su aspecto más profundo. Por ende, el estado llega a velar que todos sus ciudadanos gocen de las condiciones necesarias para vivir en un entorno saludable; en especial de los niños que pertenecen a una población vulnerable propia de su edad.

Dicha norma se condice con el artículo 4 de la misma, que reconoce a la familia como un instituto natural y fundamental de la sociedad (CNNA,2002). Este reconocimiento de la familia como una institución fundamental para la sociedad es de suma importancia para el desarrollo del presente trabajo debido a que cada medida tomada por el estado referente a la familia merece una especial consideración.

El artículo 44 de la misma, establece como uno de los deberes primordiales del estado, el garantizar la plena vigencia de los derechos humanos, en este caso específico los derechos de los niños y adolescentes (CNNA,2002). En síntesis, el estado debe proteger especialmente al niño y garantizar la plena vigencia de sus derechos, los cuales deben ser reconocidos y respetados, teniendo en cuenta su estado de vulnerabilidad.

Por otro lado, Luis Lamas Puccio (2011), expuso los siguientes argumentos:

"...el niño (...) es un sujeto de derecho de protección especial que requiere la asistencia y cuidados adecuados, necesarios y especiales para su desarrollo y bienestar, tanto antes como después del nacimiento. Este énfasis tuitivo se debe o su condición de debilidad manifiesta para llevar una vida totalmente independiente, de modo, que por la situación de intangibilidad, inmadurez o inexperiencia en que están los menores frente a los adultos, se les impone a la familia, a la comunidad, a la sociedad y al Estado, la obligación de asistir y proteger al niño para garantizar tanto su desarrollo normal y sano en aspectos biológico, psíquico, intelectual, familiar y social, como la promoción y preservación de sus derechos y el ejercicio pleno y efectivo de ellos.

Coincidimos con los argumentos esgrimidos en el anterior apartado, debido al estado de vulnerabilidad del niño(a) y adolescente es que requieren una especial protección para su correcto desarrollo integral. Siendo obligación de la sociedad y el estado garantizar el adecuado desarrollo del menor ya sea en su familia biológica u otra familia sustituta.

\section{B) El código del niño y adolescente y su exclusiva finalidad de protegerlos}

En el Perú, el niño y el adolescente tienen la facultad de desarrollarse en su núcleo familiar, con el objeto que alcancen su adecuado desarrollo psicobiológico; y en el supuesto que careciera de su familia natural, tendrá el derecho de vivir en una familia sustituta, obviamente, tal circunstancia establece que previo a estas medidas, se deberá declarar el Abandono Material y moral del aludido menor por la autoridad jurisdiccional, en la investigación correspondiente (Rojas, 2005). No obstante, son los padres los que deben ser el núcleo protector de los niños(a) y adolescentes, obligados directos y comprometidos con el desarrollo integral de sus hijos; sin embargo, en algunas veces no pueden o no quieren cumplir con ese rol y sus hijos terminan privados de sus cuidados parentales; a consecuencia de estas situaciones, es que surge el programa de acogimiento familiar como medida de protección 
más adecuada frente a la desprotección familiar en la que vivieron los niños.

Por consiguiente; el artículo 8 del CNNA, confirma una serie de lineamientos destinados a su exclusiva finalidad de protegerlos, afirmando que:

$>$ Todo niño y adolescente tiene derecho a vivir, crecer y desarrollarse en el seno de su familia.

$>$ El niño y adolescente que carecen de familia natural, tiene derecho a crecer en el seno de una familia.

$>$ El niño y adolescente no podrán ser separados de su familia natural sino por circunstancias especiales definidas en la ley y con la exclusiva finalidad de protegerlos.

Conviene enfatizar, que el lugar idóneo donde el niño(a) y adolescente puede vivir es en el seno de su familia. En cambio, es preocupante que los padres en algunos casos sean los que vulneren los derechos fundamentales de sus hijos, principalmente el derecho a la identidad, el derecho a la integridad física y psíquica; es aquí donde el estado entra a tallar, siendo el acogimiento familiar un programa de ayuda a los niños que carecen de cuidados parentales, brindándoles la oportunidad de vivir en una familia sustituta, evitando así la institucionalización del menor.

\section{C) Ley de acogimiento familiar}

El inicio de la Ley N. ${ }^{0} 30162$ "Se remonta al año 2012 donde se presentó el Proyecto de Ley 2088/2012-CR, la cual fue sancionado el 05 de diciembre del 2013 en primera votación y el 5 de enero en segunda votación por la comisión permanente, siendo publicada en el Diario Oficial El Peruano el día 29 de enero del 2014. El origen de esta ley se justificó primero en que en ese momento existían más de 9,500 niños y adolescentes internados en los diferentes Centros de Atención Residencial (CAR) públicos y privados a nivel nacional, situación que según, el legislador, los priva del derecho a vivir y desarrollarse en el seno de una familia y a interactuar libremente en la comunidad; con lo que se estaría vulnerando su interés superior y afectando a su desarrollo emocional; un segundo factor determinante en la justificación de la Ley es el lento procesos para para que alcance sus objetivos de una manera más eficaz. Declarar judicialmente a un menor en abandono ya que este puede, lamentablemente, tardar años, iniciándose a partir de esa declaración, recién el proceso de adopción; lo que acarrea como consecuencia que muchos niños en la práctica se queden institucionalizados (Defensoría del pueblo, 2010).

Para sintetizar, el acogimiento familiar fue un paso importante para la defensa de los derechos de los niños y adolescentes, debido que hasta ese momento la medida de protección principal para aquellos menores que estaba en estado de desprotección era el internamiento en los CARS, lo cual no presenta las características más adecuadas para el completo desarrollo de los menores debido a las múltiples limitaciones, sobre todo de carácter afectivo.

La promulgación de la ley de Acogimiento familiar se modificó el texto del Código de los niños y adolescentes, sustituyendo el término de colocación familiar por el acogimiento familiar (Congreso de la republica del Perú, 2014). Consideramos que la palabra acogimiento va más acorde con lo que se intenta realizar a través de este proceso dado que el valor más importante lo realizan los principales actores del acogimiento familiar que son las familias voluntarias que deciden tener la oportunidad de ayudar a los niños y con el nombre anterior 
lo que se intentaba era definir al proceso solo como una obligación del estado de buscar donde los niños puedan ser mejor cuidado.

Por consiguiente, la finalidad de la ley de acogimiento familiar es la restitución de derechos de los niños(as) y adolescentes de crecer, vivir y desarrollarse en un entorno familiar ajeno al de su familia de origen; dado que existen algunas circunstancias que impiden la permanencia del menor con su familia.

\section{2.- Organismos nacionales}

\section{A) Ministerio de la mujer y poblaciones vulnerables}

El Ministerio de la Mujer y Poblaciones Vulnerables (MIMP), es el ente rector de las políticas nacionales y sectoriales del Perú con enfoque de género sobre mujer y poblaciones vulnerables que diseña, establece, promueve, ejecuta y supervisa políticas públicas a favor de las mujeres, niños, adolescentes, personas adultas mayores, con discapacidad, desplazadas y migrantes internos, para garantizar el ejercicio de sus derechos y una vida libre de violencia, desprotección y discriminación en el marco de una cultura de paz.

Fue creado "El 29 de octubre de 1996 bajo el nombre de Ministerio de Promoción de la Mujer y del Desarrollo Humano (PROMUDEH) aunque el 11 de julio del 2002 mediante Ley Orgánica 27779, se modifica la organización del Consejo de Ministros del Perú al transformarse en el Ministerio de la Mujer y Desarrollo Social (MIMDES). Desde el 2012, se convirtió en el Ministerio de la Mujer y Poblaciones Vulnerables (Enciclopedia libre, 2016). El presente acápite hace referencia a las modificaciones del nombre que se han venido dando en el transcurso del tiempo, hoy en día llamado Ministerio de la mujer y poblaciones vulnerables.

Para concluir, las funciones generales y exclusivas del Ministerio de la Mujer y Poblaciones Vulnerables (MIMP), en el marco de sus políticas nacionales y sectoriales; se encargan de apoyar, promover y fomentar el desarrollo de programas y proyectos regionales. En ese sentido, uno de sus programas es el acogimiento familiar, el cual es de relevancia para nuestra investigación; encargado de ofrecer una especial protección a los niños(as) y adolescentes que se encuentran en total desprotección familiar, ofreciéndoles ser acogidos por una familia ajena a la suya; evitando así la institucionalización del menor.

\section{B) ONG Buckner Perú}

Especialmente promueve el derecho a vivir en familia, trabajando en el fortalecimiento familiar; formando familias prósperas en el cuidado de la salud y bienestar familiar, como también en la formación y enriquecimiento espiritual de las familias y de nuestra niñez.

"Buckner Perú es una Organización No Gubernamental que es la filial de Buckner internacional que es una organización que nació en Dallas, Texas E.E.U.U en 1879, a través del Pastor Roberto Cooke Buckner, para responder a las necesidades de orfanatos después de la guerra Civil en Texas, esta organización también tiene otras filiales que operan en la República Dominicana, Guatemala, Honduras, Kenia, México, y Perú. Inicio sus actividades desde el año 2006, en la promoción, protección y restitución de los derechos de los niños, adolescentes y familias, en situación de desprotección y vulnerabilidad, con la implementación y ejecución de programas de desarrollo y crecimiento integral en beneficio de la población vulnerable (Buckner Perú, 2016). Para sintetizar, ONG Buckner es considerado como una organización internacional, interesados en la protección de las familias y en especial de los niños(as) y 
adolescentes; que se encuentran en situación de desprotección y vulnerabilidad, para así brindarles una especial protección; a través de sus programas.

Desde el año 2007 hasta el año 2015 ha sido la primera organización de la sociedad civil en haber efectuado una Alianza con el Estado para implementar el Programa de Acogimiento Familiar en beneficio de los niños y adolescentes separados del cuidado de sus padres, habiendo restituido el Derecho de vivir en familia a alrededor de 60 niños y adolescentes, quienes tuvieron un nuevo modelo de familia (Buckner Perú, 2016). Aunado a ello se buscó familias que estén dispuestas a asumir la responsabilidad de su cuidado. Estás familias acogedoras son preparadas y acompañadas por un equipo profesional multidisciplinario, los cuales se encargan de monitorear a dichas familias con la finalidad de que estén cumpliendo los objetivos trazados.

No obstante, gran parte del conocimiento referido al acogiendo familiar se lo debemos a esta organización que de manera conjunta con el estado viene brindado su apoyo desinteresado a las poblaciones más vulnerables que en este caso serían los niños en estado de abandono. Sin embargo, estamos lejos de alcanzar objetivos significativos con respecto al número de niños acogidos en el Perú; posiblemente debido a la falta de concientización de la importancia del acogimiento familiar. Así mismo, no desmerecemos el trabajo que sigue realizando Buckner, porque ayudado a muchos niños a vivir en mejores condiciones, evitando rotundamente la institucionalización.

\section{3.- Medios de protección internacional}

\subsection{1.- Legislación internacional}

\section{A) Declaración universal de los derechos humanos}

Resaltando la importancia de la figura del acogimiento familiar es necesario hablar del reconocimiento internacional del derecho a vivir en familia.

Según la DUDH, los derechos humanos son el reconocimiento de la dignidad intrínseca y de los derechos iguales e inalienables de todos los miembros de la familia (Chunga, 2012). Concepto que compartimos debido a que goza de gran coherencia y profundidad, lo que posibilita una defensa argumentativa acorde a nuestros objetivos, es decir que el derecho de todo niño a vivir en familia deriva de su misma esencia de ser, por lo tanto, es un derecho que merecen todos los niños por igual.

Por consiguiente, la Declaración Universal de derechos humanos, proclamaron que la infancia tiene derechos a cuidados y asistencia especiales, convencidos de que la familia, como grupo fundamental de la sociedad y medio natural para el crecimiento y bienestar de todos sus miembros y en particular de los niños, debe recibir la protección y asistencia necesarias para poder asumir plenamente sus responsabilidades dentro de la comunidad (Herrera, 2012).

Reconociendo que el niño, para el pleno y armonioso desarrollo de su personalidad, debe crecer en el seno de la familia, en un ambiente de felicidad, amor y comprensión, considerando que el niño debe estar plenamente preparado para una vida independiente en sociedad y en particular, en un espíritu de paz, dignidad, tolerancia, libertad, igualdad y solidaridad.

\section{B) Convención americana de derechos humanos}

La convención Americana De Derechos Humanos, señala que el mejor lugar para el desarrollo integral del niño es la familia, donde exista felicidad, bienestar, tranquilidad, cariño, amor, respeto, comprensión etc. 
Según Aguilar (2012), los siguientes artículos de la convención americana de los derechos humanos, mencionan a la familia como el entorno saludable donde el menor puede vivir, crecer y desarrollarse:

- Artículo 17 inciso 1 de la $C A D H$, refiere que la familia es el elemento natural y fundamental de la sociedad y debe ser protegida por la sociedad y el estado.

- $\quad$ Articulo 19; respecto de los Derechos del Niño, manifiesta que todo niño tiene derecho a medidas de protección que su condición de menor requiere por parte de su familia, de la sociedad y estado.

A modo de conclusión, convencidos de que la familia es el medio natural para el crecimiento y el bienestar de todos sus miembros, y en particular de los niños, deben recibir la protección y asistencia necesarias para poder asumir plenamente sus responsabilidades dentro de la comunidad. Reconociendo que el niño, para el pleno y armonioso desarrollo de su personalidad, debe crecer en una familia, en un ambiente de felicidad, lo que supone una obligación de los estados y comunidades de brindar los cuidados adecuados, necesarios y especiales para su desarrollo y bienestar del menor.

\section{C) Carta de los derechos de familia}

La Iglesia Católica siempre sensible a los temas familiares, acordó la redacción de una Carta de los Derechos de la Familia; reafirmando su postura de defensa, desde el concepto cristiano, pero involucrando lo político, social y económico.

La Carta de los Derechos de la Familia es formulada por la Santa Sede el 22 de octubre de 1983, que considera a la familia más que una unidad jurídica social y económica, como una comunidad de amor y solidaridad, insustituible para la enseñanza y retransmisión de los valores culturales, sociales, espirituales y religiosos (Álvarez, 2001). Es sin duda un pilar en la defensa de la familia debido a que sus argumentos valen tanto para los creyentes como para los que no lo son, lo cual hoy en día pareciera un requisito indispensable para el debate de cualquier controversia referida a la familia.

Coincidimos con los argumentos esgrimidos en esta Carta de los derechos de familia. Quedando claro que el objetivo principal de la carta es la defensa de los derechos de la familia, considerándola como una comunidad de amor, cariño, respeto, ternura y cuidados necesarios, para lo cual es totalmente insustituible. Por consiguiente, la cristiana está presente en esta carta como luz de la revelación divina que esclarece la realidad natural de la familia, que derivan en definitiva de la ley inscrita por el creador en el corazón de todo ser humano.

\section{4.- Organismos internacionales}

\section{A) Red latinoamericana del acogimiento familiar}

Para la protección de los derechos de la familia y los niños, especialmente aquellos que se encuentran institucionalizados, se ha creado una institución denominada Red Latinoamericana de Acogimiento Familiar (RELAF).

Según la Red latinoamericana de acogimiento familiar (RELAF,2014), Señala que es una ong que trabaja en América latina y el Caribe, promoviendo la garantía del derecho a vivir en familia. Desde el 2008, aboga e incide en los gobiernos y organizaciones de la sociedad civil de los países, problematizando la situación de los niños, niñas y adolescentes institucionalizados, estimulando la toma de decisiones políticas, para hacer efectivo el derecho 
a la vida en familia. RELAF desarrolla en forma sostenida programas de cooperación técnica junto a socios estratégicos, dirigidos a apoyar y promover las estrategias de los gobiernos y la sociedad civil para impulsar la desinstitucionalización. En ese sentido, resulta también importante destacar que el RELAF (2014), define acogimiento familiar con las siguientes palabras: "Es un tipo de cuidado basado en la familia, que incluye oír al niño para su cuidado, sin alterar significativamente la rutina familiar. La familia continúa con su dinámica y estructura cotidiana responsabilizándose por el tiempo que sea necesario a la protección integral del niño". Es importante acotar, que varios países en América Latina (Colombia, Honduras, República Dominicana, Chile, Venezuela, Uruguay y Perú) han iniciado el proceso de desinstitucionalización en favor de los niños(as) y adolescentes.

En síntesis, la red latinoamericana de acogimiento familiar, trabaja para que los niños que están viviendo en orfanatos, privados del amor familiar y expuestos a la vulneración de sus derechos, tengan una familia de acogida, alguien con quien jugar, aprender a caminar, hablar, adultos que los aconsejen, ayuden a hacer la tarea, los cuiden cuando estén enfermos, festejen sus cumpleaños y navidades, situaciones especiales que marcan profundamente la personalidad del menor.

\section{3.- Inclusión de la modalidad de acogimiento post adoptivo en la ley 30162 , en beneficio de los niños y adolescentes en el Perú que se encuentran en estado de abandono a la luz del principio del interés superior del niño.}

\section{1.- Principio del interés superior del niño}

\section{A) Nociones preliminares del Principio del interés superior del niño}

El principio del interés superior del niño, tiene su origen en los sistemas anglosajones en donde se consideró que con el interés superior del niño se solucionarían los conflictos familiares (Vásquez, 2014). Así mismo, la evolución de los derechos de los niños en diferentes sistemas jurídicos manifiesta una característica uniforme que será el reconocimiento de sus derechos. Por consiguiente, ha sido un proceso gradual desde una primera etapa en que fueron personas prácticamente ignoradas por el derecho, considerando que los intereses de los niños eran un asunto privado, que quedaba fuera de la regulación de los asuntos públicos (López, 2013).

Por lo tanto, los niños debido a la vulnerabilidad propia de su edad, requieren protección, cariño, amor, respeto, comprensión y guía para su correcto desarrollo y este pensamiento no siempre fue compartido de igual forma. Por el contrario, anteriormente los niños eran vistos como seres humanos imperfectos, propiedad de sus padres.

\section{B) Desarrollo normativa}

El Tribunal Constitucional peruano ha señalado que el principio del interés superior del niño se encuentra implícitamente reconocido en el artículo 4 de la Constitución y en base a él las acciones del Estado, la sociedad, la comunidad y la familia, en lo que respecta a la protección de los niños y a la promoción, preservación, ejercicio y disfrute de sus derechos, deben estar orientadas a lograr su pleno bienestar físico, psíquico, moral, intelectual, espiritual y social( Gaceta jurídica, 2005). Por consiguiente, se encuentra implícitamente reconocido el principio del interés superior del niño en el código del niño y el adolescente, reconociendo su exclusiva finalidad de protegerlos, manifestando que todo niño y adolescente tiene derecho a vivir, crecer y desarrollarse en el seno de su familia (Derechos de la infancia y la adolescencia, 2013). 
Entonces, el niño(a) y adolescente tiene derecho a desarrollarse en el seno de una familia que lo cobije social y afectivamente, frente aquellas situaciones de peligro y abandono que se encuentren, siendo la familia un inmediato medio natural, teniendo en cuenta el principio del interés superior del niño. Ahora bien, para fines de la investigación corresponde señalar que es el "Acogimiento familiar", quien ofrece una especial protección a los niños que se encuentran en desprotección familiar; necesitando un hogar pasa su desarrollo integral y sobre todo afectivo, asumiendo dos obligaciones básicas en primer lugar la de respetar los derechos del niño y en segundo lugar la de garantizar el ejercicio de los mismos.

\section{2.- Declaración de abandono de los niños(as) y adolescentes en el ordenamiento peruano.}

\section{A) Nociones preliminares de abandono}

La Defensoría del Pueblo, propone en su Informe Defensoría No 150; nociones preliminares de abandono como:

"el descuido, desatención o desamparo, negligente o no, del niño, niña o adolescente por parte de las personas responsables de su cuidado (madre, padre, tutores, etc.), que tiene como presupuesto indispensable la consiguiente carencia de soporte familiar, sumada a la existencia de situaciones que afectan gravemente, en cada caso concreto, al desarrollo integral de un niño, niña o adolescente y que, a partir de esta situación de desprotección, no permiten el goce y disfrute de sus derechos fundamentales" ( Defensoría del Pueblo, 2014).

Asimismo, esta noción de abandono señala la situación de desprotección familiar en el que se encuentra el niño(a) o adolescente producto de la ausencia de los cuidados parentales y tutelares; quienes tienen la responsabilidad de cuidados, protegerlos para su correcto desarrollo integral. No obstante, constituyendo una vulneración a sus derechos fundamentales como el derecho a la identidad, el derecho a la integridad física y psíquica entre otros; los cuales están reconocidos tanto en la legislación nacional como internacional.

Mientras tanto, desde la perspectiva de la "Doctrina de la Protección Integral", la situación de abandono no representa una situación irregular, sino más bien una situación de vulneración de los derechos de los niños, niñas y adolescentes, que impone a los responsables -la familia, la sociedad y el Estado - la obligación de respetarlos, protegerlos y garantizarlos mediante determinadas acciones. Desde esta doctrina se entiende que las personas menores de edad son titulares de los mismos derechos reconocidos a los adultos y, además, son titulares de derechos específicos en su calidad de niños, niñas y adolescentes (Campoy,2016).

Esta nueva naturaleza del abandono ya no concibe la irregularidad desde la situación del niño, niña o adolescente, sino que más bien traslada la irregularidad a aquellos sujetos obligados a respetar, garantizar y proteger los derechos de los niños y niñas y adolescentes. En ese sentido, la situación de abandono exigirá más bien la restitución de aquellos derechos que fueron vulnerados mediante mecanismos especiales de protección, lo que es congruente con la concepción del niño como titular de derechos y obligaciones.

\section{B) Causales de abandono}

Existen múltiples circunstancias que dificultan o impiden la permanencia de sus hijos con sus padres. En efecto, el legislador llegara a valorar dichas circunstancias, previa investigación tutelar y determinara el estado de abandono del niño(a) y adolescente.

Algunas circunstancias se deben a; padres violentos o toxicómanos, consumo excesivo de 
sustancias, tensión de la relación en familias ensambladas, problemas educativos, descuido en la atención de enfermedades (Losanto, 2017). En el mismo sentido, existen otras circunstancias que impiden la permanencia de sus hijos con sus padres; como es la falta de apoyo o aislamiento social, toxicomanías, carencia de recursos, negligencia o falta de habilidades en el cuidado de los niños, violencia doméstica, enfermedades mentales, privación de libertad, hospitalización prolongada etc. (Feria,2014).

Al respecto, es preciso señalar que son los padres los que deben ser el núcleo protector de los niños y adolescentes, obligados directos y comprometidos con el desarrollo integral de sus hijos; sin embargo, algunas veces no pueden o no quieren cumplir con ese rol y sus hijos terminan viéndose privados de sus cuidados parentales.

Nuestra legislación señala ciertas circunstancias como causales de abandono y las enumera en el artículo $248^{\circ}$ del Código del Niño y Adolescente, para evitar que el juez actúe de forma arbitraria.

El Juez especializado podrá declarar en estado de abandono a un niño o adolescente cuando:

a) Sea expósito; b) Carezca, en forma definitiva, de las personas que conforme a la ley tienen el cuidado personal de su crianza, educación o, si los hubiera, incumplan las obligaciones o deberes correspondientes; o carecieran de las calidades morales o mentales necesarias para asegurar la correcta formación; c) Sea objeto de maltratos por quienes están obligados a protegerlos o permitir que otros lo hicieran; d) Sea entregado por sus padres a un establecimiento de asistencia social público o privado y lo hubieran desatendido injustificadamente por seis meses continuos o cuando la duración sumada exceda de este plazo; e) Sea dejado en instituciones hospitalarias u otras similares con el evidente propósito de abandonarlo; f) Haya sido entregado por sus padres o responsables a instituciones públicas o privadas, para ser promovido en adopción; g) Sea explotado en cualquier forma o utilizado en actividades contrarias a la ley 0 a las buenas costumbres por sus padres o responsables, cuando tales actividades sean ejecutadas en su presencia; h) Sea entregado por sus padres o responsables a otra persona mediante remuneración o sin ella con el propósito de ser obligado a realizar trabajos no acordes con su edad; e, i) Se encuentre en total desamparo. La falta o carencia de recursos materiales en ningún caso da lugar a la declaración del estado de abandono.

No obstante, la ley estipula taxativamente las causales para reconocer que un niño(a) o adolescente se encuentra en estado de abandono para evitar que el juez actúe de forma arbitraria. Sin embargo, hubiera sido conveniente que conjuntamente con las mencionadas causales, el legislador hubiese establecido los elementos centrales que configuran la situación de abandono, a fin de establecer los límites de interpretación para el operador jurídico, sea éste judicial o administrativo.

\section{3.- La Modalidad de acogimiento familiar post adoptivo en la Legislación comparada}

\subsection{1.- España}

En España debido a su conformación especial a raíz de las diferentes identidades sobre las que se ha construido su unidad existen las comunidades autónomas que gozan de un reconocimiento constitucional y las cuales están dotadas de cierta autonomía legislativa con representantes propios, y de determinadas competencias ejecutivas y administrativas, por lo cual en cada una de estas comunidades existe un tratamiento independiente de la figura del acogimiento familiar a diferencia de nuestro país, donde rige por una norma nacional y por una institución centralizada como lo es INABIF, la cual regula los parámetros de cada uno de los aspectos que implica el acogimiento familiar, este aspecto también es diferente en España 
donde existen instituciones colaboradoras de integración familiar (ICIFS).

La presente investigación merece un análisis individual de algunas de las comunidades autónomas de España, para poder comprender y comparar los aspectos más importantes del acogimiento familiar debido a que esta figura tiene mucho más tiempo desarrollándose en este país.

\section{A) Comunidad autónoma de Andalucía}

La Comunidad autónoma de Andalucía, otorga también una especial protección a los menores es ahí la regulación de la Ley de acogimiento familiar, la cual tiene como propósito que el niño crezca, viva y se desarrolle en una familia.

Asimismo, reconoció a los menores en estado de abandono como un colectivo doblemente vulnerable, primero por su condición de minoría en cuanto a dependencia se refiere y, segundo, por su procedencia de una situación de riesgo o desamparo que circunstancias adversas o el simple desinterés de sus progenitores los ha llevado (Programa de acogimiento familiar, 2012). Se considera a los niños, niñas y adolescentes una población vulnerable, porque al no contar con autonomía tienen una posición de desventaja para poder hacer efectivos sus derechos y libertades; la autonomía es algo que van adquiriendo progresivamente a medida que crecen y se socializan. De acuerdo al segundo apartado, existen numerosas ocasiones de niños(as) y adolescentes abandonados en lugares donde corre peligro su vida, ya no solo se trata de un tema de incumplimiento, sino que estamos en presencia del delito de exposición de personas al peligro; en estos casos, de manera particular, creemos que los padres que han cometido tal degradación no deberían recuperar de ninguna manera la tenencia de menor hijo.

La Ley 21/1987, regula el acogimiento familiar dentro de su título I (De la protección), Capitulo IV, artículos 26 a 29. El artículo 26 pretende ofrecernos el contenido del acogimiento familiar. A su vez, en este mismo precepto se nos describe el contenido de dos modalidades de Acogimiento Familiar recogidas en su artículo 29, el cual prevé que éste "Se constituirá según su finalidad de carácter simple, permanente o adoptiva" (Asociación estatal de acogimiento familiar, 2014). Modalidades aplicadas por Ley de acogimiento familiar de la Comunidad Autónoma de Andalucía, la cual considero importantes y relevantes, frente al estado de vulnerabilidad del menor. Respecto al acogimiento Simple, deberá utilizarse de modo provisional, hasta que el menor pueda reintegrarse en su familia de origen y el acogimiento adoptivo, será una prevención para una eventual adopción del mismo por parte de la familia acogedora.

Según cifras de los niños acogidos en la Comunidad autónoma de Andalucía; es de 500 niños(as) y adolescentes, acogidos anualmente (Asociación estatal de acogimiento familiar, 2016). El número de niños acogidos en la Comunidad autónoma de Andalucía es superior a las cifras de niños acogidos en el Perú, según las estadísticas que maneja el INABIF; el número total de familias acogedoras en el año 2018 fueron 100 familias. Pues, las familias postulantes tienen como pretensión el acogimiento familiar de un niño, para posteriormente realizar la adopción del niño, teniendo como consecuencia la desmotivación de estas familias con el posterior desistimiento; debido a que las familias son conscientes de que vivir con un niño implica la creación de lazos afectivos, siendo así difícil la separación del niño con su familia acogedora, es por ello la necesidad de incluir la modalidad post adoptivo con la finalidad que haya más niños acogidos y familias acogedoras.

\section{B) Comunidad autónoma de Aragón}

El acogimiento familiar es una forma de protección al menor previsto en su "Código Civil art. 
173 C.C. de la Comunidad autónoma de Aragón, que produce la plena participación del mismo en la vida de familia de acogida e impone a quien lo recibe las obligaciones de velar por él, tenerlo en su compañía, alimentarlo, educarlo y procurarle una formación integral". ${ }^{104}$ Respecto a las modalidades de acogimiento familiar la comunidad autónoma de Aragón, menciona al "Acogimiento simple"; como la reinserción del menor en su familia de origen o centros de atención residencial y por el "Acogimiento adoptivo"; constituye cuando la entidad pública eleva la propuesta de adopción ante el Juez" (Gobierno de Aragón, 2012). En relación, a la modalidad de acogimiento adoptivo, consideramos necesaria su inclusión en el ordenamiento peruano; debido a que de esta manera aumentaría el número de niños acogidos beneficiados y así existirán más familias motivadas a pertenecer al programa de acogimiento familiar.

Según cifras de los niños acogidos en la Comunidad autónoma de Aragón; es de 200 niños(as) y adolescentes anualmente (Asociación estatal de acogimiento familiar,2016). El número de niños acogidos en la Comunidad autónoma de Aragón es superior a las cifras de niños acogidos en el Perú, según las estadísticas que maneja el INABIF; el número total de familias acogedoras en el año 2018 fueron 100 familias. Las familias acogedoras son conscientes de que vivir con un niño implica la creación de fuertes lazos afectivos, siendo así difícil la separación del niño con-* su familia acogedora; ademas esta situación vulnera el interes superior del niño pues implicaria una doble perdida familiar.

\subsection{2.- Chile}

En la sociedad chilena el acogimiento de niños(as) y adolescentes se ha caracterizado, por ser un acto voluntario y de solidaridad familiar.

El programa de familias de acogida tiene su origen "El 11 de julio del año 2005, promulgándose la Ley № 20032" (Zavala, 2015). Por consiguiente, el programa de familias de acogida "Contemplan dos modalidades; el primero acogimiento familiar especializada (FAE), aquí se puede iniciar la adopción por parte de la familia acogedora; y el segundo es el acogimiento familiar simple (FAS), donde la familia acogedora permanecerá temporalmente con el niño(a) y adolescente" (Zavala,2015).

Asimismo, el programa de familias de acogida se encuentra dirigido en proporcionar al niño (a) y adolescente, que adolece de ausencia de cuidados parentales una familia distinta a su familia de origen; garantizándole así un entorno más adecuado en el que pueda crecer, vivir y desarrollarse. Respecto a las modalidades de acogimiento, cabe resaltar la modalidad de acogimiento especializado, el cual permite la adopción preferente por parte de las familias acogedoras; y en relación a nuestra investigación, consideramos necesario la inclusión de esta modalidad en el ordenamiento peruano, debido a que de esta manera aumentaría el número de niños acogidos beneficiados y así existirán más familias motivadas a pertenecer al programa de acogimiento familiar, ya que la razón de desmotivación por parte de las familias acogedoras es la imposibilidad de adopción del niño acogido, pues las familias son conscientes que desarraigar al menor de su familia acogedora sería totalmente desfavorable, debido a los fuertes lazos que han ido acrecentándose en el transcurrir del tiempo compartido.

\subsection{3.- México}

El acogimiento familiar es una medida de protección, pues estar con una familia proporciona un ámbito seguro, estable, afectivo, además de una atención individualizada y personalizada, que repercutirán positivamente en su desarrollo personal y social.

El programa de familias de acogida en México, es considerado como un modelo social de 
atención a la infancia vulnerada que tiene alrededor de 35 años de existencia, en sus inicios se llamó apoyo familiar o ayuda intrafamiliar, posteriormente colocaciones familiares y actualmente acogimiento familiar, brindándoles una familia acogedora con la finalidad de evitar así su internación en centros residenciales (Martínez, 2011). Consideramos que las familias de acogida son un sistema alternativo de cuidado infantil, para niños y adolescentes, que se encuentran en una situación de desprotección familiar. Por lo tanto, el término" Acogimiento Familiar", va más acorde con lo que se intenta realizar a través de este proceso dado que el valor más importante lo realizan los principales actores del acogimiento familiar que son las familias voluntarias que deciden tener la oportunidad de ayudar a los niños y con los nombres anteriores lo que se intentaba era definir al proceso solo como una obligación de buscar un lugar donde los niños puedan ser mejor cuidados.

Es preciso señalar, que la Ley de los Derechos de niños y adolescentes del Estado de México, hace mención en su artículo No 5 inciso veinte; que, de acuerdo a la modalidad de acogimiento post adoptivo, esta familia es aquella distinta a su familia de origen que acoge provisionalmente en su seno niños y adolescentes con fines de adopción, y que asume todas las obligaciones en cuanto a su cuidado y protección, de conformidad con el principio de interés superior de la niñez (Matamoros, 2017). Por consiguiente, la asignación de los niños y adolescentes sólo podrá otorgarse a una familia de acogida post adoptiva que cuente con "Certificado de idoneidad; dispone también que se procurará no separar a hermanas, hermanos, pero si hubiere necesidad de ello, se establecerán medidas para que mantengan vínculos de convivencia, contacto y comunicación permanente (Ávila, 2015). Es decir, el acogimiento familiar post adoptivo, es cuando una familia distinta a su familia de origen llega acoger provisionalmente al niño(a) y adolescente con fines de adopción. La familia acogedora que pretenda adoptar se le tendrá que otorgar antes un certificado de idoneidad y es a través de este documento que se determinara si la familia es apta para adoptar a un niño(a) o adolescente determinado, teniendo como finalidad prevenir o superar las dificultades que se puedan presentar en el transcurso de la convivencia.

Situación distinta al Perú, pues no permite el acogimiento post adoptivo con fines de adopción; principal motivo de desmotivación y posteriormente estas familias terminan desistiendo, debido a que las familias son conscientes de que vivir con un niño implica la creación de fuertes lazos afectivos, siendo así difícil la separación del niño con su familia acogedora; ademas esta situación vulnera el interes superior del niño pues implicaria una doble perdida familiar.

\subsection{4.- Paraguay}

Es preciso comenzar por su pilar normativo, que en este caso es su constitución nacional, el cual señala y reconoce en su artículo 54 que "La familia, la sociedad y el Estado tienen la obligación de garantizar al niño su desarrollo armónico e integral, así como el ejercicio pleno de sus derechos, protegiéndolo contra el abandono, la desnutrición, la violencia, el abuso, el tráfico y la explotación" (Martínez, 2011). Cuando nos referimos a la protección normativa no hay órgano más importante dentro de un país que su constitución, la cual garantiza la plena protección del niño(a) y adolescente, debido a su situación de vulnerabilidad propia de su edad.

Por ende, el acogimiento familiar en el código de la niñez y adolescencia de Paraguay, "Constituye la medida por la cual el Juzgado encomienda a una familia apta, el cuidado, la protección, la atención y la asistencia integral del niño, de conformidad del Código" (UNICEF, 200). Esto implica para quien ejerce la responsabilidad de prestar acogida al niño, lo realice con asistencia material y afectiva, brindándole los cuidados necesarios que necesita. 
Por consiguiente, "El 7 de octubre del 2010 - Paraguay promulgo el Decreto № 5196 por el cual se establece el programa de acogimiento familiar de niños y adolescentes sujetos a protección y apoyo", teniendo consigo una serie de modalidades de acogimiento familiar: Acogimiento Simple, permanente y adoptivo (Aguilar, 2011). En ese mismo sentido, el Decreto No 5196; resalta la modalidad de acogimiento adoptivo, definiéndola como la acción de asumir el cuidado de un niño o adolescente que por distintos motivos no puede permanecer al cuidado de su familia y tampoco ser reinsertado en su familia de origen.

Con relación al acogimiento adoptivo, es la modalidad que pretendemos incluir en la Ley de acogimiento familiar No 30162 del Perú, considerando el impacto positivo en otros países como (España, chile, México, Paraguay), trayendo consigo un mayor número de niñas, niños y adolescentes acogidos.

\subsection{5.- Colombia}

El artículo $1^{\circ}$ de su Código de la Niñez y Adolescencia, Ley 1098 de 2006, tiene por finalidad garantizar a los niños, a las niñas y a los adolescentes su pleno y armonioso desarrollo para que crezcan en el seno de la familia y de la comunidad, en un ambiente de felicidad, amor y comprensión. Prevalecerá el reconocimiento a la igualdad y la dignidad humana, sin discriminación alguna.

Asimismo, el artículo 59, establece que la ubicación en hogar sustituto es una medida de protección provisional que toma la autoridad competente y consiste en la ubicación del niño, niña o adolescente en una familia residente en el país, que se compromete a brindarle el cuidado y atención necesarios en sustitución de la familia de origen. Es decretada por el menor tiempo posible de acuerdo con las circunstancias y los objetivos que se persiguen sin que pueda exceder de seis meses. El defensor de Familia puede prorrogarla, por causa justificada, hasta por un término igual a la inicial, previo concepto favorable del jefe jurídico de la Dirección Regional del Instituto Colombiano de Bienestar Familiar. En el caso de los niños, niñas y adolescentes indígenas, su primera opción será la ubicación del menor en una familia indígena. En todos los casos con la finalidad de atender exclusivamente los gastos del niño, niña o adolescente, el hogar sustituto recibe un aporte mensual del Estado.

No obstante, es importante destacar que esta norma valora la solidaridad familiar, así como también cuida a que los menores acogidos no sufran un nuevo desarraigo familiar, ya que plantea la posibilidad y preferencia a las familias acogedoras de ser adoptantes del niño(a) o adolescente.

En ese sentido, el art 67 hace mención a la Solidaridad familiar, señalando que el Estado reconocerá el cumplimiento del deber de solidaridad que ejerce la familia diferente a la de origen, que asume la protección de manera permanente de un niño, niña o adolescente y le ofrece condiciones adecuadas para el desarrollo armónico e integral de sus derechos.

En conclusión, si alguna familia acogedora quiere adoptar al niño que está al cuidado de una familia distinta a la de origen y cumple con las condiciones de adoptabilidad, que exige el código, podrá hacerlo, a menos que la familia que tiene el cuidado del niño(a) o adolescente, decida adoptarlo.

\subsection{6.- Bolivia}

La Ley 548 del Código de la Niña, Niño y Adolescente del 17 de julio del 2014, establece en su artículo 2 de su título preliminar, que la finalidad del presente Código es garantizar a la niña, niño y adolescente, el ejercicio pleno y efectivo de sus derechos, para su desarrollo 
integral y exigir el cumplimiento de sus deberes.

Por consiguiente, en su artículo 51 del CNNA, manifiesta que, por decisión judicial, con carácter temporal o permanente, la familia sustituta acoge en su seno a una niña, niño o adolescente, obligándose a cumplir los mismos deberes de madre o padre.

La medida mencionada se efectiviza mediante la guarda, tutela o adopción, argumentándose lo dispuesto por el artículo 52: "a) Las niñas, niños y adolescentes serán oídos previamente, considerando su etapa de desarrollo, y su opinión deberá ser tomada en cuenta por la jueza o el juez en la resolución que se pronuncie; b) Valoración integral del grado de parentesco, la relación de afinidad y afectividad, su origen, condiciones culturales, región y lugar donde vive; c) Evitar la separación de sus hermanas y hermanos, salvo que ocasione un daño emocional o psicológico; d) La familia sustituta debe ser seleccionada y capacitada mediante un programa especialmente creado para este fin, para asumir sus responsabilidades en cuanto al cuidado, protección y asistencia de la niña, niño y adolescente; e) Se priorizará a las familias que se encuentren en el entorno comunitario de la niña, niño y adolescente; y, f) Garantizar a las niñas, niños y adolescentes un entorno de seguridad, estabilidad emocional y afectiva, así como una adecuada socialización".

Cabe señalar, que según lo previsto por el artículo 60, inciso III, la Instancia Técnica Departamental de Política Social puede habilitar a los guardadores para el trámite de adopción del menor a su cargo. Además, la convivencia con un menor, previa a su adopción por espacio de un año, permite excepcionalmente la posibilidad de que solicitantes mayores de cincuenta y cinco años puedan acceder a la adopción (artículo 84, inciso b). Así como también, abrevia el proceso de adopción nacional, pues, el periodo de convivencia podrá ser dispensado cuando la niña, niño o adolescente por adoptar, cualquiera fuere su edad, ya estuviere en compañía de la madre o padre adoptantes, durante el tiempo mínimo de un año (artículo 87 inciso III).

Finalmente, en caso sea otorgada la adopción, la Instancia Técnica Departamental de Política Social será la encargada de realizar el seguimiento post adoptivo.

\subsection{7.- Ecuador}

Así pues, López (2014) manifiesta que el acogimiento familiar representa, por tanto, una alternativa al acogimiento institucional. En muchos casos el acogimiento institucional puede tener efectos perjudiciales sobre el desarrollo físico y cognitivo del menor, incluso irreversibles. Siendo el estado quien garantizara la atención prioritaria al niño, niña o adolescente, en especial a los que se hallen en situación de abandono y riesgo de alejarse del seno de su familia de origen, promoviendo el derecho a vivir en una familia alternativa a través del acogimiento familiar y, en último término, cuando se hubieren agotado las medidas de apoyo al núcleo social y de reinserción.

Es importante mencionar que todas las personas a quienes se encomiende el cuidado y protección de un niño, niña o adolescente en acogimiento familiar deben estar inscritas en un programa de acogimiento que les proporcionará la formación y capacitación necesarias y supervisará el desempeño de su cometido.

El Código Orgánico de la Niñez y Adolescencia en su artículo 231.- "Opción para adoptar a niños acogidos: Las personas que hayan tenido a un niño, niña o adolescente en acogimiento familiar, tendrán opción prioritaria para su adopción, siempre que cumplan con los requisitos legales". En ese mismo sentido, la adopción tiene por objeto garantizar una familia idónea, permanente y definitiva al niño, niña o adolescente que se encuentren en aptitud social y legal para ser adoptados. 
Situación distinta al Perú, pues no permite el acogimiento post adoptivo, llegando a ocasionar innecesariamente un segundo desarraigo al menor, con las consiguientes repercusiones en su salud emocional, bienestar físico y su desarrollo integral; siendo necesario la modificación de la ley de acogimiento familiar, a efectos que sea permitido tener acceso a la adopción del menor acogido.

\section{4.- Propuesta Teórica}

\subsection{1.- La Post adopción de los niños(as) y adolescentes por sus familias acogedoras como una alternativa de solución a la problemática de los menores que se encuentran declarados en estado de abandono en el Perú.}

El acogimiento familiar en el Perú es una figura relativamente nueva, cuyo antecedente inmediato es la institución de la colocación familiar. Es con la publicación de la Ley 30162 de Acogimiento familiar, el 29 de enero de 2014, que se regula más detalladamente sus alcances, precisando los requisitos para ser considerada persona o familia acogedora; sin embargo, en el artículo 7 inciso f) excluye como futuros acogedores a quienes sean aspirantes a la adopción, exigiendo entre los documentos a presentar para la obtención del acogimiento familiar judicial, una declaración jurada de no ser aspirante a la adopción (artículo 10 inciso g). Con ello, se ha pretendido evitar que los futuros adoptantes evadan las etapas del procedimiento administrativo de adopción y recurran al acogimiento familiar, para posteriormente solicitar la adopción por excepción en la vía judicial.

Asimismo, la presente propuesta teórica está basada en brindar a los niños(as) y adolescentes en el Perú que se encuentran declarados judicialmente en estado de abandono, mayores oportunidades de vivir, crecer y desarrollarse en una familia; así como también, eliminar la actual exclusión a los acogedores familiares de ser adoptantes del menor que tienen acogido. En ese sentido se ha fundamentado la necesidad, importancia y factibilidad de que excepcionalmente, las familias acogedoras puedan solicitar la adopción de niños(as) y adolescentes, de cuyo acogimiento familiar son responsables, a través de la vía administrativa o judicial.

Por lo tanto, los niños debido a la vulnerabilidad propia de su edad, requieren protección, cariño, amor, respeto, comprensión y guía para su correcto desarrollo y este pensamiento no siempre fue compartido de igual forma. Por el contrario, anteriormente los niños eran vistos como seres humanos imperfectos, objetos, propiedad de sus padres, de conformidad por lo argumentado en el artículo $\mathrm{N}^{\circ} 4$ de la Constitución Política del Estado Peruano: Mencionando que la comunidad y el Estado protegen especialmente al niño, al adolescente, a la madre y al anciano en situación de abandono. También protegen a la familia y promueven el matrimonio. Reconocen a estos últimos como institutos naturales y fundamentales de la sociedad.

De acuerdo a lo mencionado líneas arriba, guarda colación con lo previsto por los artículos II, VIII y IX del Título Preliminar y asimismo con el artículo 8 del Código de los Niños y Adolescentes. "Artículo II.- Sujeto de derechos. - El niño y el adolescente son sujetos de derechos, libertades y de protección específica". "Artículo VIII.- Obligatoriedad de la ejecución. - Es deber del Estado, la familia, las instituciones públicas y privadas y las organizaciones de base, promover la correcta aplicación de los principios, derechos y normas establecidos en el presente Código y en la Convención sobre los Derechos del Niño". "Artículo IX.- Interés superior del niño y del adolescente. - En toda medida concerniente al niño y al adolescente que adopte el Estado a través de los Poderes Ejecutivo, Legislativo y Judicial, del Ministerio Público, los Gobiernos Regionales, Gobiernos Locales y sus demás instituciones, así como en la acción de la sociedad, se considerará el principio del interés superior del niño y del adolescente y el respeto a sus derechos. 
Pues, la exclusión de las familias acogedoras como aspirantes a la adopción del menor acogido, atenta contra el principio del interés superior del niño y vulnera su derecho fundamental a vivir en una familia. En ese sentido, el artículo 8.- A vivir en una familia. señala que el niño y el adolescente tienen derecho a vivir, crecer y desarrollarse en el seno de su familia. El niño y el adolescente que carecen de familia natural tienen derecho a crecer en un ambiente familiar adecuado. El niño y el adolescente no podrán ser separados de su familia sino por circunstancias especiales definidas en la ley y con la exclusiva finalidad de protegerlos.

son los padres los que deben ser el núcleo protector de los niños y adolescentes y los obligados directos y comprometidos con el desarrollo integral de sus hijos; sin embargo, algunas veces no pueden o no quieren cumplir con ese rol y sus hijos terminan viéndose privados de sus cuidados. La post adopción de niños, niñas y adolescentes por sus familias acogedoras, constituiría un importante avance en el respeto a los derechos de la infancia y la adolescencia, ello contribuiría al desarrollo integral de los potenciales adoptados, ya que trata de brindarles la oportunidad de continuar formando parte de una familia que lo ama, cuida y protege; evitando una doble perdida familiar que ya sufrió la separación de su familia de origen, para nuevamente someterlo al alejamiento de su familia acogedora, teniendo que iniciar un nuevo proceso de adaptación a una tercera familia.

La adopción de los niños(as) y adolescentes por parte de sus familias acogedoras se formalizaría a través de un Proceso Judicial o Administrativo, según el caso, debidamente informados por sus correspondientes Equipos Multidisciplinarios y siempre que el niño(a) y adolescente se encuentre declarado en estado de abandono y pues en una situación jurídica de adoptabilidad, escuchando su opinión en función de su edad y considerando lo más favorable a su superior interés. En ese mismo sentido, las familias acogedoras deberán reunir los requisitos necesarios y manifestar expresamente su consentimiento para la adopción, además deben estar capacitados, evaluados y monitoreados constantemente, para así demostrar su idoneidad de adoptante.

De acuerdo a la investigación realizada países como España, México, Chile, Paraguay, Colombia, Bolivia y Ecuador estipulan en sus legislaciones, la adopción de niños(as) y adolescentes por parte de sus familiares acogedoras, han dado un paso agigantado e importante y sobre todo necesario en otorgar mayores posibilidades a los niños(as) y adolescentes que se encuentran declarados en estado de abandono, encontrándose en situación de adoptabilidad de contar con una familia distinta a su familia de origen, pero con toda la disposición de brindarles los cuidados necesario e idóneos, para su correcto desarrollo integral.

El Tribunal Constitucional peruano a través de sus jurisprudencias se ha manifestado al interés superior del niño y a su derecho a vivir en una familia. Destacando la sentencia del expediente 04058-2012-PA/TC, cuyos fundamentos 15, 19 y 25 constituyen doctrina jurisprudencial vinculante:

15.... Convención sobre los Derechos del Niño establece, entre otras disposiciones, las siguientes:

Artículo 3

En todas las medidas concernientes a los niños que tomen las instituciones públicas o privadas de bienestar social, los tribunales, las autoridades administrativas o los 
órganos legislativos, una consideración primordial a que se atenderá será el interés superior del niño.

Los Estados Partes se comprometen a asegurar al niño la protección y el cuidado que sean necesarios para su bienestar.

\section{Artículo 27}

1. Los Estados Partes reconocen el derecho de todo niño a un nivel de vida adecuado para su desarrollo físico, mental, espiritual, moral y social.

2. A los padres u otras personas encargadas del niño les incumbe la responsabilidad primordial de proporcionar, dentro de sus posibilidades y medios económicos, las condiciones de vida que sean necesarias para el desarrollo del niño....

19. ....el principio constitucional de protección del interés superior del niño, niña y adolescente presupone que los derechos fundamentales del niño, niña y adolescente, y en última instancia su dignidad, tienen fuerza normativa superior no solo en el momento de la producción de normas, sino también en el momento de la interpretación de ellas, constituyéndose por tanto en un principio de ineludible materialización para el Estado, la sociedad en su conjunto y la propia familia, incluidos claro está el padre, la madre o quien sea el responsable de velar por sus derechos fundamentales....

25. ...conviene subrayar que el principio del interés superior del niño, comprende, entre otras cosas, una actuación tuitiva por parte de los operadores jurisdiccionales, a quienes corresponde la adecuación y flexibilización de las normas y la interpretación que de ellas se realice, a fin de lograr la aplicación más favorable con el fin de dar solución a la controversia reclamada, siendo de especial importancia este principio toda vez que se trata niños, niñas y adolescentes, que tienen especial cuidado ....

En síntesis, la doctrina de la protección integral todavía no ha sido totalmente alcanzada ni desarrollada por el Estado peruano, en la medida en que algunas normas y un importante número de funcionarios y servidores públicos que las aplican, mantienen una visión de los menores de edad como "objetos" de protección y no como sujetos de derechos, los cuales merecen una especial protección.

La Corte Suprema a través de la Casación N 688-2016-Moquegua, publicada en el diario el peruano el 30 de enero de 2018, señalo como argumentos para declarar fundada la demanda, teniendo en cuenta el interés superior del niño, derecho a su identidad y el derecho que tiene de vivir en una familia.

PRIMERO: A) y B) del numeral III de la presente resolución, referentes al interés superior del niño y su derecho a la identidad, resulta menester precisar previamente que, en cuanto al interés superior del niño...

SEGUNDO: Que la Constitución Política del Perú en su artículo 1 y 2 inciso $1^{\circ}$, consagra el derecho del niño a tener una familia (...)

TERCERO: Que la Constitución Política del Perú en su artículo 2 inciso $1^{\circ}$, consagra el derecho del niño a la identidad (...).

CUARTO: Que en cuanto a la finalidad de la adopción el artículo 115 del Código de los 
Niños y Adolescentes establece: "La adopción es una medida de protección (...).

SEXTO: "El examinado presenta, una familia estructurada de buen soporte emocional familiar (...) presenta una personalidad extrovertida, muestra buena predisposición, muestra control emocional, pasible, sociable y activo. Su estado emocional se encuentra estable, seguro de sí mismo (...) presenta sentimientos de afecto y cariño por la niña en cuestión y proyecta identificación paternal", lo que evidencia la salud mental y psicológica...

Existiendo así otra forma excepcional de adoptar a un menor de edad, que no se encuentra recogida en la Ley, pero que ha sido establecida por la Corte Suprema a través de la Casación $\mathrm{N}^{\circ}$ 688-2016-Moquegua, publicada en el diario el peruano el 30 de enero de 2018, que permite a las familias con acogimiento familiar de un menor, puedan demandar judicialmente la adopción por excepción.

Son los niños(as) y adolescentes quienes no solo son el futuro de mañana, sino también el presente del mundo, encarnando la promesa viva de que el mundo se puede transformar en un mejor lugar, es por ello la especial protección que debemos brindarle, debido a su estado de vulnerabilidad, el cual es propio de su edad. Considerando al acogimiento familiar como una alternativa de solución frente a la desprotección familiar vivida por el menor y son las familias de acogida quienes los cuidaran, amaran, protegerán y no para explotarlos o abusarlos, sino para colaborar, compartir y orientarlos en el difícil proceso de su desarrollo integral.

En pocas palabras, son nuestras familias quienes nos conducen en la forma de ver el mundo, pensar, comportarnos y valorar la vida y la de los otros. Por esa razón, se reitera la enorme necesidad de brindar a los niños(as) y adolescentes peruanos declarados en estado de abandono, mayores oportunidades de vivir en una familia, encontrando así una alternativa de solución en permitir el acceso a las familias acogedoras la oportunidad de convertirse en adoptantes del niño(a) o adolescente acogido.

El Estado también tiene la obligación de asegurar que ninguna persona llegue a sufrir algún tipo de discriminación; en el presente caso en particular, sería la exclusión de acceder a la adopción de niños(as) y adolescentes, por parte de sus familias acogedoras, de conformidad con lo señalado por la Constitución Política en su artículo 2 inciso 2) Nadie debe ser discriminado por motivo de origen, raza, sexo, idioma, opinión, condición económica o de cualquier otra índole.

En ese sentido, considero que la familia acogedora no debe ser excluida para ser adoptante del niño(a) y adolescente que tiene en acogimiento, avalar esto es totalmente discriminatorio, al no permitirle la experiencia paterno o materno filial, y que en algunos casos pueden unirlos vínculos consanguíneos o de afinidad.

La presente propuesta teórica tiene sus bases en:

a) El derecho de los niños(as) y adolescentes a vivir en una familia y a no ser separados de ella, especialmente en aquellos niños que se encuentran declarados judicialmente en estado de abandono, Vivir en familia es, no sólo un derecho fundamental de la infancia, sino también, el modo más eficaz para garantizar el adecuado desarrollo de los niños, niñas y adolescentes y la satisfacción de sus necesidades. Lastimosamente, aun cuando estén en acogimiento familiar, su situación jurídica no está certeramente definida, como sí sucede cuando se realiza adopción. 
b) Las familias acogedoras puedan solicitar la adopción de niños(as) y adolescentes, de cuyo acogimiento familiar son responsables, a través de la vía administrativa o judicial, según el caso, debidamente informados por sus correspondientes Equipos Multidisciplinarios y siempre que el niño(a) y adolescente se encuentre declarado en estado de abandono y pues en una situación jurídica de adoptabilidad, escuchando su opinión en función de su edad y considerando lo más favorable a su superior interés. En ese mismo sentido, las familias acogedoras deberán reunir los requisitos necesarios y manifestar expresamente su consentimiento para la adopción, además deben estar capacitados, evaluados y monitoreados constantemente, para así demostrar su idoneidad de adoptante.

c) El Estado peruano tiene la obligación de garantizar el interés superior del niño, lo que Significa que, en todas las decisiones, el interés superior de los niños, niñas y adolescentes es un principio rector que funda nuestro ordenamiento jurídico en todas aquellas materias que los involucran. Significando que en que todas las decisiones que se tomen en relación a un niño, niña o adolescente deben ir orientadas a su bienestar y pleno ejercicio de derechos.

d) Nadie debe ser discriminado por motivo de origen, raza, sexo, idioma, opinión, condición económica o de cualquier otra índole. Siendo el estado quien tiene la obligación de asegurar que ninguna persona sufra algún tipo de discriminación; en este caso en particular, sería la exclusión de acceder a la adopción de niños, niñas y adolescentes, por ser su familia acogedora. Pues, la familia acogedora no debe ser excluida para ser adoptante del niño(a) y adolescente que tiene en acogimiento, avalar esto es totalmente discriminatorio, al no permitirle la experiencia paterno o materno filial.

Si se incluye una nueva modalidad de acogimiento familiar, en la Ley 30162, como "Acogimiento Post Adoptivo", entonces habrá un mayor número de niñas, niños y adolescentes acogidos que están declarados en estado de abandono y existirán más familias motivadas a pertenecer al programa de acogimiento familiar de INABIF, permitiéndoles tener una familia junto a su familia acogedora, evitando la reinserción del niño en los centros de atención residencial, considerando a la institucionalización como último ratio, ya que conllevan toda una serie de déficits psicológicos y afectivos que marcan profundamente la personalidad del menor.

En síntesis, la exclusión de las familias acogedoras como aspirantes a la adopción del menor acogido, atenta contra el principio del interés superior del niño y vulnera su derecho fundamental a vivir y permanecer en una familia, al negarle la posibilidad de que en determinadas circunstancias, puedan ser adoptados por sus acogedores familiares, con quienes ya viven una experiencia de familia y que en algunos casos pueden unirlos vínculos consanguíneos o de afinidad, llegando a ocasionar innecesariamente un segundo desarraigo al menor, con las consiguientes repercusiones en su salud emocional, bienestar físico y su desarrollo integral; siendo necesario la modificación de la ley de acogimiento familiar, a efectos que sea permitido tener acceso a la adopción del menor acogido.

\section{5.- Desarrollo del proyecto de Ley con la finalidad de incluir la modalidad de Acogimiento Post adoptivo en la Ley No 30162.}

La familia acogedora podrá solicitar: 
La familia acogedora legitimada iniciara el trámite por excepción normado en el artículo 128 del código de los niños y adolescentes o también iniciar el trámite de adopción administrativa según corresponda, adquiriendo la familia acogedora la calidad de adoptantes preferentes del niño, niña o adolescente acogido.

En tal sentido, la post adopción los niños(as) y adolescentes por parte de sus familias acogedoras se formalizaría a través de un proceso judicial o administrativo según el caso, debidamente informados por sus correspondientes Equipos Multidisciplinarios y siempre que el niño(a) y adolescente se encuentre declarado en estado de abandono y pues en una situación jurídica de adoptabilidad, escuchando su opinión en función de su edad y considerando lo más favorable a su superior interés. En ese mismo sentido, las familias acogedoras deberán reunir los requisitos necesarios y manifestar expresamente su consentimiento para la adopción, además deben estar capacitados, evaluados y monitoreados constantemente, para así demostrar su idoneidad de adoptante.

\section{A) Exposición de motivos del Proyecto de Ley}

Por lo tanto, consideramos necesaria la posibilidad de incluir la Modalidad de Acogimiento Post adoptivo en la Ley 30162.

La iniciativa de incluir la modalidad de acogimiento post adoptivo, tiene como objetivo el aumento del índice de niños acogidos, así como también el número de familias acogedoras, permitiéndoles tener una familia junto a su familia acogedora, como medida de protección en situación de vulnerabilidad por su interés superior. Teniendo como objetivo, evitar la institucionalización del niño, el cual consideramos que debe ser de ultimo ratio. Normándose así el procedimiento para acceder y la documentación para ser presentada por la familia acogedora en la vida judicial y en vía administrativa.

Se evitaría un doble desarraigo del menor, que ya sufrió la separación de su familia de origen, para nuevamente someterlo a la pérdida de su familia acogedora, teniendo que iniciar un nuevo proceso de adaptación a una tercera familia acogedora.

La Ley de acogimiento familiar establece el acogimiento familiar como una medida transitoria, que se aplica a los niños, niñas y adolescentes en situación de abandono o desprotección familiar. En ese sentido, la Ley de acogimiento familiar № 30162 del Perú, en su artículo $\mathrm{N} 07$ literal $\mathrm{F}$, menciona como exclusiones de acogimiento familiar que la familia acogedora no puede posteriormente solicitar la adopción ya que esto es una medida de protección transitoria y la familia acogedora no podrá acceder a la adopción del niño o adolescente acogido.

Las presentes omisiones de la Ley No 30162, respecto a la exclusión de las familias acogedoras como aspirantes a la adopción del menor acogido, atenta contra los principios de protección especial e interés superior del niño y vulnera su derecho fundamental a vivir y permanecer en una familia, al negarle la posibilidad de que en determinadas circunstancias, puedan ser adoptados por sus acogedores familiares, con quienes ya viven una experiencia de familia, llegando a ocasionar innecesariamente un segundo desarraigo al menor, con las consiguientes repercusiones en su salud emocional, bienestar físico y su desarrollo integral; siendo necesario la modificación de la ley de acogimiento familiar, a efectos que sea permitido tener acceso a la adopción del menor acogido. Asimismo, la familia acogedora al convertirse en adoptantes, también seguirá ejerciendo su cuidado bajo los mismos parámetros legales y obligaciones de la tutela regulada en el Código Civil.

Permitiría contribuir en el ejercicio de los derechos al libre desarrollo, igualdad y no 
discriminación por parte de sus familias acogedoras, adquiriendo la familia acogedora la calidad de adoptantes preferentes del niño, niña o adolescente acogido.

Se enfatizaría la concreción del derecho de la infancia y la adolescencia peruana a vivir y permanecer en una familia y a no ser separados donde puedan vivir, crecer y desarrollarse, concretando su desarrollo integral del menor.

\section{B) Análisis costo - beneficio}

El presente proyecto, no generara gasto nacional. Lo único que se pretende es incluir la modalidad post adoptiva, repercutiendo favorablemente en el incremento del número de niños acogidos que se encuentren en situación de desprotección familiar. Además de incrementar el número de familias acogedoras motivadas a permanecer en el banco de familias acogedoras. Permitiéndoles a los menores tener una familia junto a su familia acogedora, como medida de protección en su situación de vulnerabilidad por su interés superior, evitando la institucionalización del niño, el cual consideramos que debe ser de ultimo ratio.

Se evitaría un doble desarraigo del menor acogido, que ya sufrió con la separación de su familia de origen, para nuevamente someterlo a la pérdida de su familia acogedora, teniendo que iniciar un nuevo proceso de adaptación a una tercera familia acogedora.

\section{Conclusiones}

La inclusión de la modalidad de acogimiento post adoptivo en la ley 30162, beneficiaria a los niños y adolescentes en el Perú que se encuentran en estado de abandono, entonces habrá un mayor número de niños acogidos y por ende existirán más familias motivadas a pertenecer al programa de acogimiento familiar, debido a que las familias son conscientes de que vivir con un niño implica la creación de fuertes lazos afectivos, siendo así difícil la separación del niño con su familia acogedora; además esta situación vulnera el interés superior del niño pues implicaría una doble perdida familiar.

El Acogimiento Familiar es una figura jurídica, que nace del derecho constitucional de toda persona a tener una familia, que consiste en integrar a un menor en estado de abandono a una familia no constituida por sus padres biológicos, con la finalidad de garantizar el derecho del niño, niña y adolescente a vivir en una familia. Además, es el Estado quien se encarga de proveer las condiciones necesarias para su libre desarrollo del menor y también velar por su seguridad y bienestar. Es por esto que el estado como ente protector, ha creado el programa de acogimiento familiar como medida de protección más adecuada frente a la desprotección familiar, siendo el primer lugar de crecimiento del ser humano.

Resulta innegable la importancia de la Familia como base fundamental para una sociedad y a través del Acogimiento familiar; es donde existe la restitución del Derecho del niño, niña y adolescente a vivir en una familia; es decir hace referencia a la reposición y restablecimientos de derechos de vivir en un entorno familiar ajeno al de su familia de origen, cuando su familia no se encuentra en condiciones de hacerlo, familias que atraviesan por múltiples circunstancias que impiden la permanencia con sus hijos o hijas. Hoy en día tanto las legislaciones, organismos nacionales como internacionales brindan protección a los derechos del Niño a vivir en una familia, considerando como el entorno más favorable para el menor donde puedan vivir, crecer y desarrollarse, debido a su estado de vulnerabilidad 
propio de su edad.

La exclusión de las familias acogedoras como aspirantes a la adopción del menor acogido, atenta contra el Principio del Interés superior del Niño, el que debe guiar toda formulación y aplicación normativa en lo que versa sobre la protección de niños(as) y adolescentes; de esta manera la inclusión de la modalidad de acogimiento familiar post adoptivo, pretende salvaguardar no solo la integridad física de los menores, sino también su integridad emocional. Considerando que desarraigar al menor de su familia acogedora sería totalmente desfavorable, debido a los fuertes lazos que han ido acrecentándose en el transcurrir del tiempo compartido.

\section{Bibliografía}

1. AGUILAR LLANOS, Benjamín. Derecho de Familia. Perú, Editorial Legales E.IR.L.2012.

2. ALIAGA GAMARRA, Jimena Beatriz. "El Interés Superior del Niño y Adolescente en la Adopción Internacional en el Perú". Tesis para optar el Título de Abogado, Lima. Pontificia Universidad Católica del Perú., 2013.

3. ALVAREZ CAPEROCHIPI JOSE. Derecho de Familia. Lima, EDICION GRIJLEY. 2001.

4. ASOCIACIÒN ESTATAL DE ACOGIMIENTO FAMILIAR. El acogimiento familiar en España. España, ASEAF,2014.

5. ASOCIACIÒN ESTATAL DE ACOGIMIENTO FAMILIAR. La vinculación de los menores acogidos con la familia acogedora.2010 [ubicado el $4 \mathrm{~V}$ 2016]. Obtenido en https://www.aseaf.org/qué-es-el- acogimiento-familiar/tipos-de-acogimiento-familiar/

6. ÀVILA VILLEGAS, Eruviel. "Ley que regula los centros de asistencia social y las adopciones en el estado de México", 2015 [ubicada el 19.XI 2017]. Obtenido en file://C:/Users/Yulissa/Downloads/LEY\%20QUE\%20REGULA\%20LOS\%20CENTROS $\% 20 D E \% 20$ ASISTENCIA\%20SOCIAL.pdf

7. BELDA USERO, Raquel. Técnicos especialistas de menores de la Generalidad Valenciana Temario. España, Editorial Alcalá de Guadaíra (Sevilla), 2005.

8. BUCKNER PERU. Contribuyendo con el Fortalecimiento Espiritual de los Niños y Familias.2016 [ubicado el 5 X 2016]. Obtenido en http://www.bucknerperu.org/com.

9. CARDENAS RODRIGUEZ, Luis. "Actualidad Jurídica", Revista del Foro, No 243, febrero 2014.

10. CHUNGA LAMONJA, Fermín. Los derechos del niño y su protección en los derechos humanos, Lima, Editorial Grijley, 2012.

11. Congreso de la República del Perú. Ley de Acogimiento Familiar. 2014.

12. DEFENSORÍA DEL PUEBLO. El derecho de los niños, niñas y adolescentes a vivir en una familia: la situación de los centros de atención residencial estatales desde una mirada de la Defensoría del Pueblo. Serie de Informes Defensorías-Informes No150, Lima, 2010.

13. DEL VALLE, Jorge. El acogimiento Familiar en España: implantación y retos actuales. 2009 [ubicado el $10 \mathrm{~V}$ 2016]. Obtenido en http://www.papelesdelpsicologo.es/pdf/1654.pdf.

14. ENCICLOPEDIA LIBRE. Ministerio de la mujer y poblaciones vulnerables del Perú, 2016 [ubicada el 25.XI 2004]. Obtenido en https:// Enciclopedia Libre.orgi/Ministerio_de_la_Mujer_y_poblaciones_Vulnerables_del_Per\%C3\%BA.

15. FERIA TANDAZO, Alejandrina. Problemas Legislativos respecto a la remoción del acogimiento familiar en el Perú. Tesis para optar el grado de Bachiller, Lambayeque. Universidad Nacional Pedro Ruiz Gallo, 2014.

16. GACETA JURİDICA. La Constitución Comentada, LIMA, G.J, 2005. 


\section{GOBIERNO DE ARAGON. Acogimiento Familiar. 2012 [ubicado} el $\quad 11 \quad$ IX 2016].http://iass.aragon.es/adjuntos/menores/programadeacogimientofamiliar.pdf

18. HERRERA MARTINIANO, Marisa. convención sobre los derechos del niño, Argentina, Editorial La Ley, 2012.

19. INTITUTO NACIONAL DE BIENESTAR FAMILIAR : Pagina institucional ,INABIF [ubicado el 17 VI 2016].Obtenido en http://www.inabif.gob.pe/portalinabif/intranet/01 doc/inabif.htm

20. INTITUTO NACIONAL DE BIENESTAR FAMILIAR. Informe de sistematización. Lima, INABIF, 2013.

21. JIMÉNEZ AYBAR, Ivan. Acogimiento Familiar. Aspectos Jurídicos y Sociales, Madrid, editorial Rialp, 2001.

22. JIMENEZ GARCIA, CRISTINA. El acogimiento familiar en España. Una evaluación de resultados, Madrid, OI, 2008.

23. Jurisprudencia Justicia Penal Juvenil. Configuración Constitucional de la Protección de los Niños y Adolescentes.2010 [ubicado el $08 \mathrm{~V}$ 2016]. Obtenido en http:///www.mpfn.gob.pe/escuela/contenido/actividades/docs/3310 4. procesal pen al ancash.pdf.

24. LAMAS PUCCIO, Luis. Diálogo con la jurisprudencia, Revista Gaceta Jurídica No 42, Julio 2011.

25. Ley de Acogimiento Familiar N³0162. Diario el peruano del 29 de enero del 2014.

26. LOPERA LOPERA, José. Manuel Técnico de Acogimiento Familiar, Lima, Ediciones Legales, 2014.

27. LOPEZ CONTRERAS, Rony. "Interés superior de los niños y niñas: Definición y contenido".

28. LOSANTO VELASCO, Marcela. Cada niño y niña cuenta. Situación de derechos de los niños y niñas que perdieron el cuidado familiar o están en riesgo de perderlo, $1^{\circ} \mathrm{Ed}$, Bolivia, 2017,

29. LOSANTO VELASCO, Marcela. Cada niño y niña cuenta. Situación de derechos de los niños y niñas que perdieron el cuidado familiar o están en riesgo de perderlo, $1^{\circ} \mathrm{Ed}$, Bolivia, 2017,

30. MARTINEZ RABANAL, Víctor. Análisis evaluativo del programa familia de acogida especializada de SENAME, México, Editorial F.A.E, 2011.

31. MARTINEZ RABANAL, Víctor. Análisis evaluativo del programa familia de acogida especializada de SENAME, México, Editorial F.A.E, 2011.

32. MATAMOROS SUR, Mariano. Gaceta del Gobierno del estado de México. [ubicado el 17 XI 2017]. Obtenido en http://www.leyderechosinfancia.mx/wpcontent/uploads/2015/05/Ley-Estado-de- Mexico.pdf

33. MELLA BALDOVINO, Ana Miluska. Acogimiento Familiar merece infraestructura administrativa adecuada y supervisión constante. Revista Gaceta Civil, Tomo 8Numero 4. Ed. Gaceta Jurídica. Febrero2014.

34. PRESIDENCIA DE LA REPÙBLICA. "Derechos de la infancia y la adolescencia Principales instrumentos y normas internacionales y nacionales", Colombia, PDR, 2013.

35. Programa de acogimiento familiar. Por el derecho a la convivencia familiar $y$ comunitaria. sistema de información para la infancia) 2014 [ubicado el 12 v 2016]. obtenido en http://www.inau.gub.uy/.../familia/acogimiento-familiar.

36. PROGRAMA DE ACOGIMIENTO FAMILIAR. Ver el mundo de otra manera.2012 [ubicado el 11IX2016].Obtenidoenhttp://iass.aragon.es/adjuntos/menores/programadeacogimien tofamiliar.pdfk 
37. Revista Latinoamericana de Ciencias Sociales, febrero 2013.

38. Silva Gálvez, Ariana. Lima, Comunicación Personal sobre acogimiento familiar. Socióloga de INABIF-Lima, 18 de Julio del 2016.

39. VAN DER HOEVEN, Henrike. Manual De Acogimiento Familiar, Lima 10 edic, 2014.

40. VÁSQUEZ BRAVO, Cecilia. "Necesidad de introducir la terminación anticipada en los procesos seguidos contra los adolescentes infractores, en aplicación del principio del interés

41. ZAVALA RUBILAR, María. "Acogimiento familiar en chile: análisis de los perfiles familiares y del ajuste de niños". Tesis para optar el grado de Doctora en Psicología, Chile. Universidad de Sevilla, 2015.

\section{Editor}

Dra. Dora Ojeda Arriaran

\section{Cómo citar este trabajo (llenado por la revista)}

Tineo Espino, Y y Ojeda Arriarán, D. (2021). Aportaciones del derecho natural en la construcción de los derechos humanos. IUS: Revista de Investigación de la Facultad de Derecho, Vol. 11 (No. 1), doi: 10.35383/ius-usat.v10i1.614

\section{Financiación}

El presente artículo no cuenta con financiación específica de agencias de financiamiento en los sectores público o privado para su desarrollo y/o publicación.

\section{Conflicto de interés}

El autor / Los autores del artículo declara(n) no tener ningún conflicto de intereses en su realización.

c Los autores. Este artículo es publicado por la IUS - Revista de Investigación de la Facultad de Derecho, Universidad Católica Santo Toribio de Mogrovejo.

Este es un artículo de acceso abierto, distribuido bajo los términos de la Licencia Creative Commons Atribución-NoComercial-CompartirIgual 4.0 Internacional (CC BY-NC-SA 4.0), que permite el uso no comercial, distribución y reproducción en cualquier medio, siempre que la obra original sea debidamente citada. 